\title{
Neuronal Pentraxin 1 Negatively Regulates Excitatory Synapse Density and Synaptic Plasticity
}

\author{
(D) Joana Figueiro-Silva, ${ }^{1,2}$ Agnès Gruart, ${ }^{3}$ Kevin Bernard Clayton, ${ }^{1,2}$ Petar Podlesniy, ${ }^{1,2}$ Maria Alba Abad, ${ }^{1,2}$ \\ Xavier Gasull, ${ }^{4,5}$ José María Delgado-García, ${ }^{3}$ and Ramon Trullas ${ }^{1,2,5}$ \\ ${ }^{1}$ Neurobiology Unit, Institut d'Investigacions Biomèdiques de Barcelona, Consejo Superior de Investigaciones Científicas (CSIC), 08036 Barcelona, Spain, \\ ${ }^{2}$ Centro de Investigación Biomédica en Red sobre Enfermedades Neurodegenerativas (CIBERNED), Instituto de Salud Carlos III, Madrid, Spain, ${ }^{3}$ División \\ de Neurociencias, Universidad Pablo de Olavide, 41013 Sevilla, Spain, ${ }^{4}$ Laboratory of Neurophysiology, School of Medicine, University of Barcelona, 08036 \\ Barcelona, Spain, and 5Institut d'Investigacions Biomèdiques August Pi i Sunyer (IDIBAPS), 08036 Barcelona, Spain
}

In mature neurons, the number of synapses is determined by a neuronal activity-dependent dynamic equilibrium between positive and negative regulatory factors. We hypothesized that neuronal pentraxin (NP1), a proapoptotic protein induced by low neuronal activity, could be a negative regulator of synapse density because it is found in dystrophic neurites in Alzheimer's disease-affected brains. Here, we report that knockdown of NP1 increases the number of excitatory synapses and neuronal excitability in cultured rat cortical neurons and enhances excitatory drive and long-term potentiation in the hippocampus of behaving mice. Moreover, we found that NP1 regulates the surface expression of the Kv7.2 subunit of the Kv7 family of potassium channels that control neuronal excitability. Furthermore, pharmacological activation of Kv7 channels prevents, whereas inhibition mimics, the increase in synaptic proteins evoked by the knockdown of NP1. These results indicate that NP1 negatively regulates excitatory synapse number by modulating neuronal excitability and show that NP1 restricts excitatory synaptic plasticity.

Key words: excitatory synapses; Kv7.2 potassium channels; long-term potentiation

\section{Introduction}

Neurons adjust the number of synapses with adjacent cells according to the level of neuronal activity through structural changes in axonal boutons and dendritic spines (Holtmaat and Svoboda, 2009; Caroni et al., 2012). This activity-dependent structural plasticity of neurons is considered to be the basis of long-term memory formation (Bailey and Kandel, 2008). It has long been hypothesized that enduring forms of enhanced synaptic plasticity require not only the activation of positive regulators that facilitate memory storage, but also the removal of mechanisms that limit the formation of new synapses (Abel and Kandel, 1998). However, although knowledge of the molecular mechanisms that promote synaptogenesis is accumulating, less is known about the factors that limit synapse formation.

In addition to synapse density, neuronal activity also controls neuronal survival (West et al., 2002). Indeed, low neuronal activ-

\footnotetext{
Received June 21, 2014; revised Feb. 5, 2015; accepted Feb. 24, 2015.

Author contributions: R.T. designed research; J.F.-S., A.G., K.B.C., P.P., M.A.A., X.G., J.M.D.-G., and R.T. performed research; R.T. contributed unpublished reagents/analytic tools; J.F.-S., A.G., K.B.C., M.A.A., X.G., J.M.D.-G., and R.T. analyzed data; J.F.-S., A.G., K.B.C., J.M.D.-G., and R.T. wrote the paper.

This work was supported by the Ministerio de Economia y Competitividad of Spain, Grants SAF2011-23550 (R.T.), BFU2011-29089 (J.M.D.-G.), BFU2011-29286 (A.G.), 2014SGR1165, Retic RD12/0034/003 and FIS PI14/00141 (X.G.); by the European Community Grant FP7/201714 (A.G.), and by CIBERNED Grant PI2013/08-3 (R.T.). We thank Dr Alvaro Villarroel for kindly providing the 5Myc-KCNQ2 and 2HA-KCNQ3 CDNAs, and Dr Joan Blasi for kindly providing the syntaxin $1 A$ cDNA.

The authors declare no competing financial interests.

Correspondence should be addressed to Dr Ramon Trullas, Neurobiology Unit IIBB/CSIC, IDIBAPS, CIBERNED., Rosselló 161, 08036 Barcelona, Spain. E-mail: ramon.trullas@iibb.csic.es.

DOI:10.1523/JNEUROSCI.2548-14.2015

Copyright $\odot 2015$ the authors $\quad 0270-6474 / 15 / 355504-18 \$ 15.00 / 0$
}

ity triggers the mitochondrial program of apoptotic cell death in mature neurons (D’Mello et al., 1993). Neuronal pentraxin 1 (NP1) is part of the intrinsic program of apoptotic cell death evoked by low neuronal activity and contributes to apoptotic neurodegeneration in mature neurons (DeGregorio-Rocasolano et al., 2001). NP1 is predominantly expressed in the nervous system (Schlimgen et al., 1995) and belongs to the subfamily of long pentraxins that interact with a number of proteins in a calciumdependent manner (for review, see Gewurz et al., 1995). In addition to NP1, two other genes encode long pentraxins in the nervous system: neuronal pentraxin with chromo domain (NPCD) and neuronal pentraxin 2 (NP2). NPCD encodes several cytosolic protein isoforms generated by alternative splicing that are mainly associated with the inner side of the plasma membrane (Chen and Bixby, 2005; Tseng and Bixby, 2011). On the other hand, NP2 is a secreted protein that is induced and dynamically regulated by high neuronal activity (Tsui et al., 1996), and is synaptogenic when overexpressed in cultured spinal neurons (O'Brien et al., 1999). This synaptogenic effect of NP2 has been attributed to its ability to bind and recruit AMPA receptors at excitatory synapses (O’Brien et al., 2002).

In contrast to NP2, NP1 is induced by low neuronal activity (DeGregorio-Rocasolano et al., 2001). The opposite effect that neuronal activity has on the expression of these neuronal pentraxins indicates that they have different functions (DeGregorioRocasolano et al., 2001). Low neuronal activity induces the expression of NP1, which accumulates in mitochondria where it regulates mitochondrial transport and dynamics (Clayton et al., 
2012). Moreover, NP1 contributes to the synaptic damage and to the subsequent apoptotic neurotoxicity evoked by amyloid- $\beta$, indicating that, in addition to cell death, NP1 also modulates synaptic function (Abad et al., 2006). This suggests that NP1 may be part of the mechanism whereby low neuronal activity downregulates synapse density. Interestingly, brain tissue from patients with late-onset Alzheimer disease exhibits a marked increase in NP1 in dystrophic neurites (Abad et al., 2006). Based on this previous evidence, we hypothesized that NP1 could be one of the factors by which low neuronal activity reduces synapse density. We have now investigated the role of NP1 in the regulation of synapse number and plasticity and found that, in contrast with other long neuronal pentraxins, NP1 limits the formation of excitatory synapses.

\section{Materials and Methods}

Cortical cell cultures. Experiments were performed in cultured cortical neurons from Sprague-Dawley $18 \mathrm{~d}$ rat fetuses of either sex prepared as described previously (Abad et al., 2006). Neurons were plated at a density of $2 \times 10^{5}$ cells $/ \mathrm{cm}^{2}$ for biochemical studies, $1 \times 10^{5}$ for immunocytochemical experiments, or at a very low density $\left(5 \times 10^{3} \mathrm{cells} / \mathrm{cm}^{2}\right)$ with primary support following the procedure previously described (Fath et al., 2009) on poly-L-lysine-coated $(100 \mu \mathrm{g} / \mathrm{ml})$ plates or $12 \mathrm{~mm}$ no. 1.5 coverslips. All procedures involving animals and their care were approved by the ethics committee of the CSIC, the ethics committee of the University of Barcelona, CEEA, and were conducted in accordance with institutional guidelines in compliance with national (BOE 34/1137011421,2013 ) and international (NIH Guide for the Care and Use of Laboratory Animals) laws and policies.

Lentiviral vectors and transduction of cortical neurons with lentiviral particles. The self-inactivating bicistronic lentiviral transfer vector constructs pWPI-NP1 and pLVTHM-shNP1 and pLVTHM-shRandom were obtained as previously described (Abad et al., 2006). The map and the sequences of these plasmids are available at Addgene. As a rescue control, the site-mutated NP1 vector pWP-resNP1 was generated by introducing seven silent mutations (G447A, C450T, A451T, G452C, C454A, C456A, C459G; numbers refer to coding DNA reference sequence) within the NP1 sequence targeted by shNP1 with the QuikChange Lightning Site-Directed Mutagenesis Kit (Agilent Technologies; Fig. 1A). Concentrated stocks of high-titer lentiviral vectors pseudotyped with vesicular stomatitis virus $\mathrm{G}$-glycoprotein were obtained as previously described (Clayton et al., 2012), stored at $-20^{\circ} \mathrm{C}$, and used within 1 month. The mean viral titer of the concentrated stocks was $7 \times$ $10^{9} \mathrm{TU} / \mathrm{ml}$. Immediately after plating, high-titer lentiviral particles were added to the growth medium of cortical cell cultures to a final concentration of $\sim 3 \times 10^{7} \mathrm{TU} / \mathrm{ml}$. After $24 \mathrm{~h}$ of incubation with the lentivirus, the medium was replaced with serum-free neurobasal supplemented with B27 (Invitrogen); $48 \mathrm{~h}$ after lentiviral transduction the percentage of cortical neurons expressing GFP was $80-90 \%$.

SDS-PAGE and Western blot analyses. Protein extracts from cultured cortical neurons treated with lentiviral particles were obtained 12-19 d after transduction. Cortical cells were solubilized in SDS sample buffer (62.5 mu Tris-HCl, pH 6.8, 2\% SDS, 10\% glycerol, $100 \mathrm{~mm}$ DTT, and $0.01 \%$ bromophenol blue), warmed at $85^{\circ} \mathrm{C}$ for $3 \mathrm{~min}$, and sonicated. The samples were loaded and electrophoresed on Novex $4-12 \%$ Bis-Tris Gels or Novex 6\% Tris-Glycine Gels (Invitrogen), depending on the molecular weight of the protein to be detected, and transferred to polyvinylidene difluoride (PVDF) membranes (Millipore). Blots were blocked with $5 \%$ nonfat dry milk in Tris-buffered saline containing $0.1 \%$ Tween 20, and then incubated with primary antibodies. We used the following antibodies: mouse anti-NP1 antibody (1:1000; Becton Dickinson), mouse anti-synaptophysin, clone SY38 (1:1000), mouse antiPSD95 (1:2000; both from Millipore Bioscience Research Reagents), rabbit anti-Kv7.2 (1:200; Alomone Labs), mouse anti-syntaxin 1A (HPC-1 clone, 1:2000; Sigma-Aldrich), mouse anti-HA (1:3000, Covance), and mouse anti-Myc (9E10 clone, 1:5000; Sigma-Aldrich). Peroxidase-conjugated goat anti-mouse IgG (1:10,000; Cell Signaling
Technology) and anti-rabbit IgG (1:5000; Cell Signaling Technology) were used as secondary antibodies. For immunoprecipitation experiments, we used peroxidase-conjugated goat anti-mouse IgG (light chainspecific) and peroxidase-conjugated monoclonal mouse anti-rabbit IgG (light chain-specific; both used at 1:10,000; Jackson ImmunoResearch Laboratories) to avoid the masking of the bands of interest by denatured heavy chains. To control for the amount of protein loaded, we used a rabbit anti-actin 20-33 antibody (1:3000; Sigma-Aldrich). Immunoreactive proteins were visualized using an enhanced chemiluminescence detection system (SuperSignal West Dura; Pierce) and bands were detected with a VersaDoc Model 5000 Imaging System (Bio-Rad). Quantification of band intensity was performed within the linear range of the chemiluminescence reaction using Quantity One computer software (Bio-Rad). The densitometric values of the bands representing NP1, synaptophysin, and PSD95 immunoreactivity were normalized to the values of the corresponding actin bands.

Immunofluorescence. Mature cortical cultures were rinsed briefly in PBS (136 mM NaCl, $2.7 \mathrm{~mm} \mathrm{KCl,} 10.1 \mathrm{~mm} \mathrm{Na}_{2} \mathrm{HPO}_{4} \cdot 2 \mathrm{H}_{2} \mathrm{O}, 1.76 \mathrm{~mm}$ $\mathrm{KH}_{2} \mathrm{PO}_{4}$ ) and fixed in methanol at $-20^{\circ} \mathrm{C}$ for $5 \mathrm{~min}$. Cells were blocked for $30 \mathrm{~min}$ in $10 \%$ BSA/PBS or $5 \%$ normal goat serum (NGS)/PBS (for NP1, VGLUT1, and Kv7.2). Incubation with primary antibodies was performed overnight at $4^{\circ} \mathrm{C}$ with the following antibodies, diluted in $3 \%$ BSA/PBS or 1\% NGS/PBS (NP1, VGLUT1, and Kv7.2): mouse monoclonal anti-PSD95 (1:50; Abcam), anti-gephyrin (1:100; Synaptic Systems), anti-NP1 (1:50, BD Transduction), rabbit polyclonal anti-synaptophysin (1:100; Synaptic Systems), anti-Kv7.2 (1:100; Alomone Labs), and guinea pig anti-VGLUT1 (1:200; Millipore Bioscience Research Reagents). The following day, the cells were washed and incubated in secondary antibodies, AlexaFluor anti-mouse-488, anti-rabbit-488, anti-mouse532, anti-mouse-633, anti-rabbit-633, and anti-guinea pig-633 (1:500; Invitrogen), for $1 \mathrm{~h}$ at room temperature. Control experiments performed for each fluorophore in the absence of primary antibody showed that this concentration of secondary antibodies did not exhibit significant background staining under the imaging conditions used. Following washes, coverslips were mounted on glass slides using Prolong Gold Anti-Fade (Invitrogen). For detection of the surface levels of GluA1, a slightly different protocol was followed. Mature cortical cells were incubated in conditioned medium containing rabbit polyclonal anti-GluA1 (1:100; Alomone Labs) for $1 \mathrm{~h}$ at $4^{\circ} \mathrm{C}$. Cells were subsequently washed in ice-cold PBS and fixed in $4 \% \mathrm{PFA} / 2 \%$ sucrose for $10 \mathrm{~min}$ at $4^{\circ} \mathrm{C}$ followed by fixation with methanol at $-20^{\circ} \mathrm{C}$ for $5 \mathrm{~min}$. Following blocking in $10 \% \mathrm{BSA} / \mathrm{PBS}$, the cells were incubated in guinea pig anti-VGLUT1 diluted in 3\% BSA/PBS for $90 \mathrm{~min}$ at room temperature. Washes were performed using $3 \%$ BSA/PBS before incubation with secondary antibody (AlexaFluor anti-rabbit-532 and anti-guinea pig-633 at 1:500; Invitrogen) for $1 \mathrm{~h}$ at room temperature. Cells were washed in PBS and coverslips were mounted using Prolong Gold Anti-Fade (Invitrogen).

Imaging and analysis. Images were acquired using a $63 \times$ oil objective (numerical aperture $=1.40$ ) on a Leica TCS-SPE confocal at $1024 \times$ 1024 resolution. Each channel was scanned separately using identical settings for laser power and photomultiplier gain/offset within each experiment. Acquisition settings were adjusted to eliminate crosstalk or bleed-through between different channels. Control experiments omitting primary antibody were included in all image acquisitions and settings adjusted to ensure that all of the secondary antibodies used did not exhibit significant immunofluorescence. As separate studies had shown that analysis of single slices and maximum projections of stacks produced equivalent results, single slices, focused using differential interference contrast (DIC), were used for colocalization analysis. To mark punctal sites, a single threshold was determined for each antibody in each experiment; this threshold was used to create a mask that was copied and pasted onto a similar threshold-created mask of the complementary antibody signal so that only the regions that showed overlap between the two signals remained. Neurites were marked on the DIC image using the ImageJ plug-in NeuronJ (Meijering et al., 2004). Pasting this mask onto the colocalizations of the presynaptic and postsynaptic markers resulted in an image containing only those colocalizations that were found along neurites. Analysis of these colocalizations was performed using the "Analyze Particles" module of ImageJ (Abramoff et al., 2004). The number of 
A

Neuronal Pentraxin 1 resistant to silencing by shNP1 RNAi

mRNA

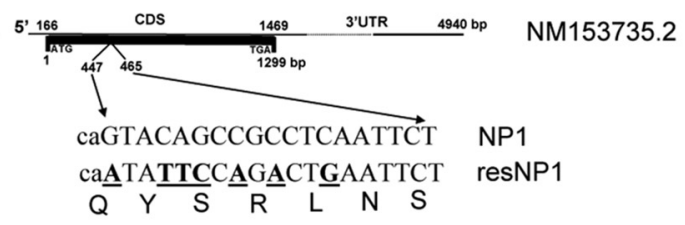

C

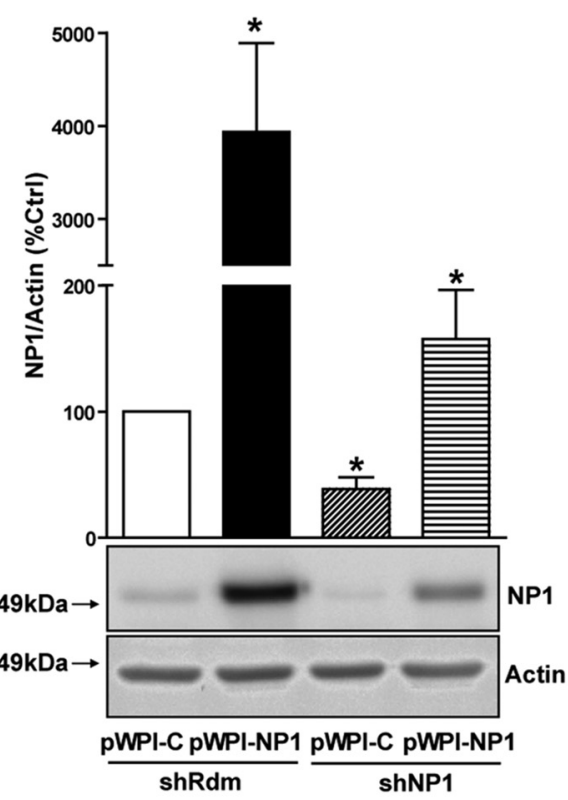

E

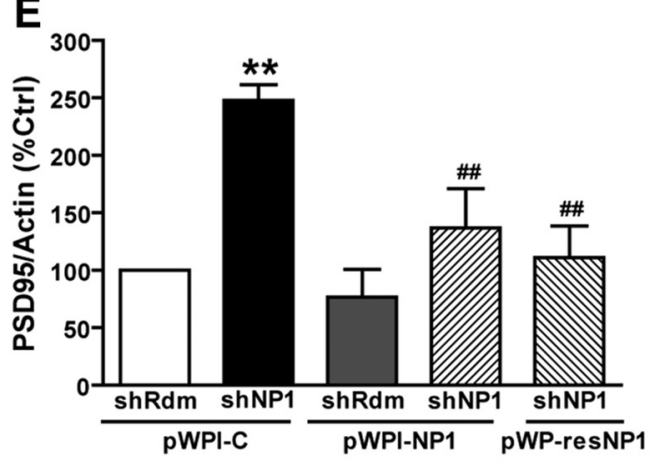

shRdm $\overline{\text { pWPI-C pWPI-NP1 pWPI-C pWPI-NP1 }}$
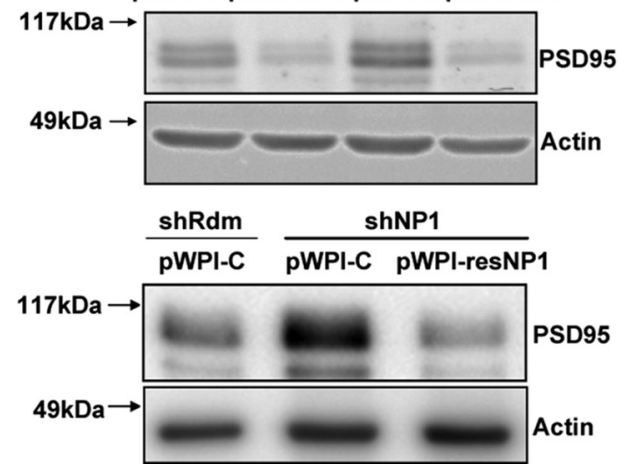
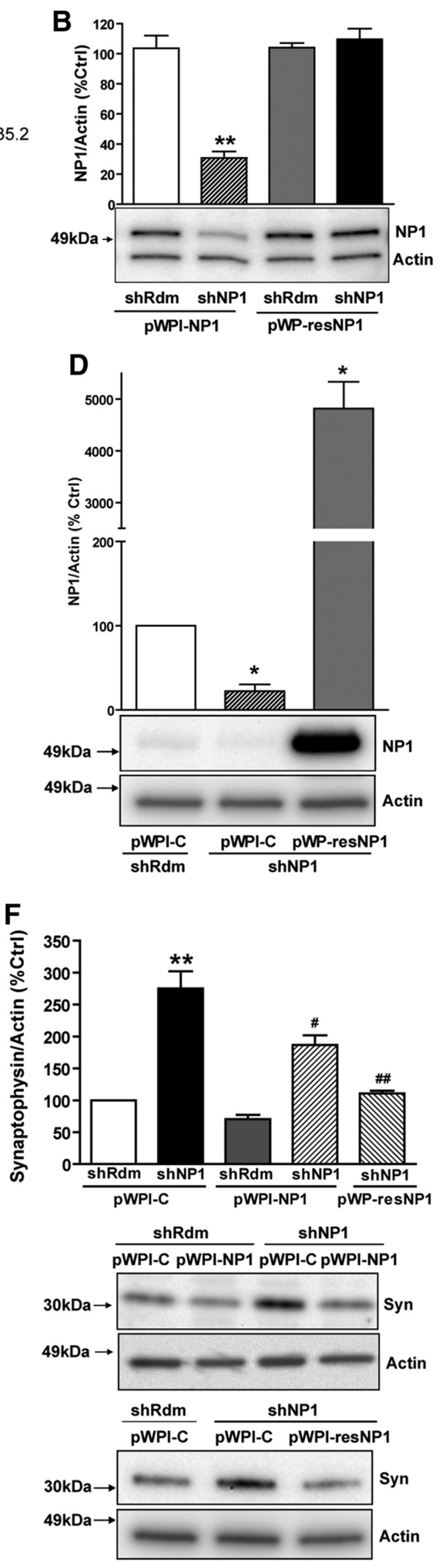
colocalizations was then divided by the length of the neurites for each image as determined by NeuronJ. To assess colocalizations using orthogonal sectioning, stacks were taken to encompass the entire depth of the cell at a $z$-step automatically selected by the confocal software. Images were adjusted using ImageJ and orthogonal sectioning performed using the OrtView plug-in for ImageJ. Quantification of dendritic protrusions was performed on 4\% PFA-fixed neurons expressing the GFP reporter that indicates transduction with either shNP1 or shRdm. Number of protrusions with a length between 0.5 and $3 \mu \mathrm{m}$ were measured. Lengths of protrusions were determined by measuring the distance between the tip and the base. Total number of protrusions, including spines (0.5-1.5 $\mu \mathrm{m})$ and filopodia $(1.6-3 \mu \mathrm{m})$, were measured in $50 \mu \mathrm{m}$ sections of dendrites using ImageJ.

Calcium imaging. Cortical cell cultures were seeded on $25-\mathrm{mm}-$ diameter glass coverslips at $2 \times 10^{5}$ cells $/ \mathrm{cm}^{2}$ and transduced with lentiviral vectors at the time of plating, as described above. Mature cortical cultures were loaded with $5 \mu \mathrm{M}$ Fura-2 AM (Invitrogen) for $1 \mathrm{~h}$ at $37^{\circ} \mathrm{C}$. Following washes in Locke-HEPES ( $154 \mathrm{~mm} \mathrm{NaCl}, 5.6 \mathrm{~mm} \mathrm{KCl}, 3.6 \mathrm{~mm}$ $\mathrm{NaHCO}_{3}, 5.6 \mathrm{~mm}$ D-glucose, $10 \mathrm{~mm}$ HEPES, $1.3 \mathrm{~mm} \mathrm{CaCl}_{2}$ ), the coverslips containing the Fura-2-loaded cells were transferred into a viewing chamber and mounted on the stage of an inverted Olympus IX70 microscope using a TILL monochromator as a source of illumination and a $40 \times$ oil objective. Images were taken with an attached cooled CCD camera (Orca II-ER; Hamamatsu Photonics) and were digitized, stored, and analyzed using Aquacosmos software (Hamamatsu Photonics). Image pairs were obtained alternatively every $5 \mathrm{~s}$ at excitation wavelengths of $340(\lambda 1)$ and $380 \mathrm{~nm}(\lambda 2 ; 10 \mathrm{~nm}$ bandwidth filters $)$ to excite the $\mathrm{Ca}^{2+}$. bound and $\mathrm{Ca}^{2+}$-free forms of the ratiometric Fura-2 dye, respectively. The emission wavelength was $510 \mathrm{~nm}(120 \mathrm{~nm}$ bandwidth filter). Typically, $10-20$ cells were present in a field and $\left[\mathrm{Ca}^{2+}\right]_{\mathrm{i}}$ values were calculated and analyzed individually for each cell from the 340 to $380 \mathrm{~nm}$ fluorescence ratios at each time point. The fluorescence ratio $(r=\mathrm{F} 340 /$ F380) of Fura-2 was converted to $\left[\mathrm{Ca}^{2+}\right]_{\mathrm{i}}$ from the following formula: $\left[\mathrm{Ca}^{2+}\right]_{\mathrm{i}}=K d \times\left[\left(R-R_{\min }\right) /\left(R_{\max }-R\right)\right] \times \beta$ (Grynkiewicz et al., 1985). The dissociation constant $(K d)$ used for Fura- 2 was 224 nм and $\beta$ was the ratio of fluorescence excited at $380 \mathrm{~nm}$ in the absence and presence of

$\leftarrow$

Figure 1. Effect of gain, loss, and rescue of NP1 function on synaptic proteins. NP1 expression was silenced by lentiviral-mediated transduction of a shRNAi sequence directed against NP1 mRNA (shNP1). Rescue experiments were performed by transgene overexpression of NP1 with two different vectors: pWPI-NP1, expressing wild-type NP1, and pWP-resNP1, expressing a site-mutated NP1 that is resistant to knockdown. Values are mean \pm SEM of $n$ independent experiments. $\boldsymbol{A}$, The site-mutated NP1 rescue control vector pWP-resNP1 was generated by introducing seven silent mutations (G447A, C450T, A451T, G452C, C454A, C456A, C459G; numbers refer to coding DNA sequence) within the NP1 sequence targeted by shNP1. $\boldsymbol{B}$, Representative Western blot and densitometric analysis of NP1/actin expression in HEK 293T cells. The resistance of resNP1 to silencing by shNP1 was tested in HEK 293T cells $24 \mathrm{~h}$ after transfection. A lentiviral vector carrying a silencing cassette expressing a shRNAi against no known target (shRdm) was used as a control for knockdown experiments. An empty pWPI-C lentiviral vector was used as a control for transgene overexpression experiments. Actin was used as a control for protein loading. The densitometric values of the bands representing NP1 immunoreactivity were normalized to the values of the corresponding actin band. shNP1 decreases transgene overexpression of wild-type NP1 by $\sim 70 \%$, whereas resNP1 is resistant to knockdown (**significantly different from pWP-NP1/shRdm, Bonferroni post hoc comparisons, $p<0.01, n=3$ ). $\boldsymbol{C}-\boldsymbol{F}$, Studies performed in mature cortical neurons in culture. $\boldsymbol{C}$, Representative Western blots and quantitative analysis of the effect of shNP1 and pWPI-NP1 on NP1 protein levels (pWPI-C/ shRdm, $n=7 ;$ pWPI-NP1/shRdm, $n=5 ;$ pWPI-C/shNP1, $n=7$; pWPI-NP1/shNP1, $n=6$ ). $\boldsymbol{D}$, Representative Western blot and quantitative analysis of the effect of shNP1 and pWP-resNP1 on NP1 protein levels (*significantly different from pWPI-C/shRdm, all $p<0.05$, Bonferroni posthoc tests; pWPI-C/shRdm, $n=4$; pWPI-C/shNP1, $n=4$; pWP-resNP1/shNP1, $n=4) . \boldsymbol{E}, \boldsymbol{F}$, Representative Western blots and quantitative analysis of the effect of NP1 knockdown and rescue on PSD95 and synaptophysin protein levels. Actin was used as normalization control. $\boldsymbol{E}$, shRdm/pWPI-C, $n=12 ;$ shNP1/pWPI-C, $n=11 ;$ shRdm/pWPI-NP1, $n=5 ;$ shNP1/pWPI-NP1, $n=7 ;$ shNP1/pWP-resNP1, $n=3 . F$, shRdm/pWPI-C, $n=15 ;$ shNP1/pWPI-C, $n=15 ;$ shRdm/ pWPI-NP1, $n=7 ;$ shNP1/pWPI-NP1, $n=7$; shNP1/pWP-resNP1, $n=3{ }^{* *}$ significantly different from shRdm/pWPI-C; $p<0.01$; \#significantly different from shNP1/pWPI-C; \#p $<0.05$; $\#$ \# $<0.01$, Bonferroni post hoc tests).
$\mathrm{Ca}^{2+}$. The calibration constants, $R_{\max }$ and $R_{\min }$, were measured using ionomycin and EGTA, respectively. In some experiments, tetrodotoxin (TTX) was added to the cells to a final concentration of $5 \mu \mathrm{M}$ to check the effect of blocking action potentials on the $\left[\mathrm{Ca}^{2+}\right]_{\mathrm{i}}$ oscillations.

Identification of NP1-binding proteins by MALDI-TOF mass spectrometry. NP1 immunoprecipitation was performed using the Seize-X mammalian Immunoprecipitation kit (Pierce) following the manufacturer's instructions. To avoid contamination of the sample with the light and heavy chains of the antibody, $50 \mu \mathrm{g}$ of the polyclonal anti-NP1 (Becton Dickinson) was immobilized to the protein G-Sepharose support using the cross-linker DSS (disuccinimidyl suberate). Approximately $1 \times 10^{8}$ neurons were lysed and subsequently incubated with the immobilized antibody overnight at $4^{\circ} \mathrm{C}$. Proteins bound to the antibody were eluted, reduced, and separated on a $10 \%$ SDS-PAGE. The gel was stained with silver nitrate and the bands were excised manually from the gel and then digested individually with $100-150 \mathrm{ng}$ of trypsin (Promega) at $37^{\circ} \mathrm{C}$ overnight using a Montage In-Gel Digest (Millipore) following the manufacturer's instructions. The resulting peptides were dried, dissolved in $0.1 \%$ TFA, and analyzed by a MALDI-TOF Voyager DE Pro mass spectrometer (Applied Biosystems).

Immunoprecipitation. To confirm the interaction of NP1 with KCNQ2, NP1 immunoprecipitation was performed in protein extracts from either total brain to assess interaction of native proteins or from HEK 293T cells transfected with recombinant rat NP1, rat syntaxin 1A, human KCNQ2, and human KCNQ3 cDNAs. The KCNQ2 and KCNQ3 cDNAs were kindly provided by Dr Alvaro Villarroel (Unidad de Biofísica, Consejo Superior de Investigaciones Científicas, CSIC-UPV/ EHU, Leioa, Spain) and were tagged at the N-terminal with a tandem repeat of five myc and two HA epitopes, respectively, as previously described (Alaimo et al., 2009). The syntaxin 1A cDNA was kindly provided by Dr Joan Blasi (Laboratory of Cellular and Molecular Neuroscience, Universitat de Barcelona, IDIBELL, L'Hospitalet de Llobregat, Spain; Pérez-Brangulí et al., 2002). HEK 293T cells were transfected using a standard calcium phosphate transfection protocol. After $24 \mathrm{~h}$, the cells were washed twice with PBS on ice and lysed in immunoprecipitation buffer ( $50 \mathrm{~mm}$ Tris-HCl, pH 7.5, $100 \mathrm{~mm} \mathrm{NaCl}, 2 \mathrm{~mm} \mathrm{CaCl}_{2}, 0.5 \%$ Triton $\mathrm{X}-100)$ containing the complete mini-EDTA-free protease inhibitor cocktail (Roche). The lysate was incubated for $20 \mathrm{~min}$ on ice and centrifuged at $4^{\circ} \mathrm{C}$ at $10,000 \times g$ for $10 \mathrm{~min}$ to remove insoluble components. For total rat brain extraction, the whole rat brain was homogenized in 10 volumes of immunoprecipitation buffer ( $50 \mathrm{~mm}$ Tris- $\mathrm{HCl}, \mathrm{pH} 7.5,100$ $\mathrm{mm} \mathrm{NaCl}, 2 \mathrm{~mm} \mathrm{CaCl}_{2}, 1 \%$ Triton X-100) containing the mini-EDTAfree protease inhibitor cocktail (Roche). The lysate was centrifuged at $1000 \times g$ for $5 \mathrm{~min}$ and the supernatant was incubated $1 \mathrm{~h}$ at $4^{\circ} \mathrm{C}$ and centrifuged at $50,000 \times g$ for $15 \mathrm{~min}$. The immunoprecipitation of the supernatants, both 293T and total brain, was performed with Dynabeads (Invitrogen) following the manufacturer's instructions. Briefly, lysates were incubated for $20 \mathrm{~min}$ at room temperature with Dynabeads previously bound to $2 \mu \mathrm{g}$ of mouse anti-NP1 antibody (Becton Dickinson), mouse anti-HA (1:3000; Covance), or mouse anti-Myc (9E10 clone, 1:5000; Sigma-Aldrich). As a control for immunoprecipitation, we used 2 $\mu \mathrm{g}$ of ChromePure mouse or rabbit IgG whole molecule (Jackson ImmunoResearch Laboratories). After immunoprecipitation, the beads were washed three times with PBS, eluted in SDS sample buffer for $5 \mathrm{~min}$ at $85^{\circ} \mathrm{C}$, and subjected to Western blotting with the corresponding antibodies.

Electrophysiological recordings. Whole-cell patch-clamp recordings were performed in primary cortical cultured neurons at room temperature using standard techniques. Recordings were performed using an Axopatch 200B amplifier (Molecular Devices). Signals were filtered at 2 $\mathrm{kHz}$, digitized at $10 \mathrm{kHz}$, and acquired with pClamp 9 software. Data were analyzed with Clampfit 9 (Molecular Devices) and Prism 4 (GraphPad Software). Filled electrodes had a resistance between 4 and $6 \mathrm{M} \Omega$. Series resistance was always $<10 \mathrm{M} \Omega$ and compensated at $70-80 \%$. For recording mEPSCs, patch pipettes were filled with the following (in $\mathrm{mm}$ ): 136.5 K-gluconate, $17.5 \mathrm{KCl}, 9 \mathrm{NaCl}, 1 \mathrm{MgCl}_{2}, 10$ HEPES-KOH, pH 7.2, and 0.2 EGTA adjusted to $290 \mathrm{mOsm} / \mathrm{kg}$. Routinely, an ATPregenerating mix (2 mM ATP, $10 \mathrm{~mm}$ phosphocreatine, $0.5 \mathrm{~mm}$ GTP, 2 $\mathrm{mm} \mathrm{MgCl}_{2}$, and $25 \mathrm{U} / \mathrm{ml}$ creatine phosphokinase) was added to the in- 
ternal solution. Extracellular saline solution contained the following (in $\mathrm{mm}$ ): $137 \mathrm{NaCl}, 5 \mathrm{KCl}, 3 \mathrm{CaCl}_{2}, 0.5 \mathrm{MgCl}_{2}, 10$ glucose, and 5 HEPES$\mathrm{NaOH}, \mathrm{pH} 7.3$, at $310 \mathrm{mOsm} / \mathrm{kg}$. To record excitatory mEPSCs, $2 \mu \mathrm{M}$ TTX, $10 \mu \mathrm{m}$ picrotoxin, and $10 \mu \mathrm{m}$ bicuculline were added to the recording chamber. Neurons were voltage-clamped at $-70 \mathrm{mV}$ and mEPSCs were recorded over a period of 10-20 min.

$\mathrm{M}$-current recordings were done in the presence of $2 \mu \mathrm{M}$ TTX using the same extracellular solution. Patch pipettes were filled with the following (in $\mathrm{mm}$ ): $160 \mathrm{~K}$-acetate, $3 \mathrm{MgCl}_{2}$, and 20 HEPES, pH 7.2. To record both $\mathrm{A}$ - and $\mathrm{M}$-currents, neurons were held at $-70 \mathrm{mV}$. Outward currents were elicited by depolarization at $-20 \mathrm{mV}$, followed by M-current deactivation at $-40 \mathrm{mV}$, as described previously (Shahidullah et al., 2005). The A-current was measured at the peak elicited by the $-20 \mathrm{mV}$ pulse or by fitting a single exponential function to the deactivation phase and then measuring its amplitude from the extrapolated fitted line as previously described (Shahidullah et al., 2005). The amount of $\mathrm{M}$-current was obtained by measuring the current relaxation at $-40 \mathrm{mV}$.

Current-clamp recordings were performed with a patch-clamp amplifier (Axopatch 200B, Molecular Devices). Patch electrodes were fabricated in a Flaming/Brown micropipette puller P-97 (Sutter Instruments). Electrodes had a resistance between 4-7 M $\Omega$ and were filled with the same solution used for the patch-clamp experiments. The extracellular solution was also the same as that used in voltage-clamp experiments. All recordings were done at room temperature $\left(22^{\circ} \mathrm{C}-23^{\circ} \mathrm{C}\right)$. After achieving the whole-cell configuration, the amplifier was switched to current-clamp bridge mode. To study neuronal excitability, we examined the resting membrane potential; action potential current threshold elicited by $1 \mathrm{~s}$ current pulses in $0.1 \mathrm{nA}$ increments; whole-cell input resistance calculated from the value at the end of a $1 \mathrm{~s}$ hyperpolarizing pulse of $-0.1 \mathrm{nA}$. Repetitive discharge was measured by counting the spikes evoked by a $1 \mathrm{~s}$ intracellular pulse of $+50 \mathrm{pA}$ depolarizing current or by counting the spikes elicited at threshold current. In experiments investigating the influence of neurotransmission on neuronal excitability, synaptic transmission was blocked with $20 \mu \mathrm{M}$ bicuculine, $20 \mu \mathrm{M}$ CNQX, and $100 \mu \mathrm{M}$ AP7. In experiments investigating the contribution potassium channels directly activated by calcium, fast after-hyperpolarization (AHP) was measured after inducing neuronal firing with short-depolarizing pulses ( $2 \mathrm{~ms}$ pulses in $10 \mathrm{pA}$ increments); short depolarizing pulses were used to avoid superimposition of the stimulation pulse and the action potential. When threshold was reached, AHP was measured from the action potential generated. In experiments to investigate the effect of shNP1 on slow after-hyperpolarization (sAHP) this was measured after suprathreshold depolarizing pulses of $100 \mathrm{~ms}(250$ $\mathrm{pA})$ or $1 \mathrm{~s}(50 \mathrm{pA})$ duration.

Measurement of cell surface receptor levels. Mature cortical neuron cultures were biotinylated using the Cell Surface Protein Isolation Kit (Pierce) following the manufacturer's protocol. Cells were washed twice with cold PBS and incubated at $4^{\circ} \mathrm{C}$ with biotinylation reagent $(0.25$ $\mathrm{mg} / \mathrm{ml}$ sulfo-NHS-SS-Biotin; Pierce) for $30 \mathrm{~min}$ with gentle agitation. The biotinylation reaction was stopped by addition of cold quenching solution (Pierce). Cells were lysed and solubilized proteins were incubated for $1 \mathrm{~h}$ at room temperature with Immobilized NeutrAvidin Gel slurry (Pierce). The bound biotinylated proteins were eluted by incubating for $1 \mathrm{~h}$ at room temperature with SDS-PAGE buffer $(62.5 \mathrm{~mm}$ Tris$\mathrm{HCl}, \mathrm{pH} 6.8,1 \%$ SDS, $10 \%$ glycerol, and $50 \mathrm{~mm}$ DTT) followed by centrifugation for $2 \mathrm{~min}$ at $1000 \times \mathrm{g}$. Biotinylated proteins were separated in $8 \%$ SDS-PAGE and transferred to PVDF membranes (Millipore), which were probed with one of the following antibodies: rabbit anti-Kv7.2 antibody (1:2000; Alomone Labs), rabbit anti-GluA1 antibody (1:1000; Millipore), mouse monoclonal anti-GluA2 antibody (1: 1000; Neuromab), and mouse monoclonal anti-GluN1 (1:2000; Becton Dickinson) as described above. We used actin as a loading control and as a standard control to ensure that there was no biotinylation of intracellular proteins. In addition, we used a sodium/potassium ATPase antibody $(1: 7500$; Abcam) as a plasma membrane marker to assess biotinylation of membrane proteins. The labeling of proteins was visualized by ECL and quantified as described above. The proportion of the different proteins at the surface was determined by measuring the band densities of both biotinylated surface receptor and total receptor in the lysate.

Surgery for chronic recordings in behaving animals. C57BL/ 6 male mice (2- to 3-months-old) were anesthetized with $4 \%$ chloral-hydrate. A total of 20 animals were implanted with bipolar stimulating electrodes aimed at the right Schaffer collateral-commissural pathway of the dorsal hippocampus ( $2 \mathrm{~mm}$ lateral and $1.5 \mathrm{~mm}$ posterior to bregma; depth from brain surface, 1.0-1.5 mm; Paxinos and Watson, 1986), and with a recording electrode aimed at the ipsilateral stratum radiatum underneath the CA1 area (1.2 mm lateral and $2.2 \mathrm{~mm}$ posterior to bregma; depth from brain surface, $1.0-1.5 \mathrm{~mm}$ ). These electrodes were made of $50 \mu \mathrm{m}$, Teflon-coated tungsten wire (Advent Research Materials ). The final position of the hippocampal electrodes was determined using as a guide the field potential depth profile evoked by paired (40 ms interval) pulses presented at the Schaffer collateral pathway (Gruart et al., 2006). During the same surgical step, 10 animals were injected with $2 \mu \mathrm{l}\left(1.5 \times 10^{7} \mathrm{TUs}\right)$ of the stock solution of the shNP1 lentiviral vector. The injection was aimed at the pyramidal cell layer at the intermediate point between the stimulating and recording electrodes and was performed with the help of a motorized Hamilton syringe at a rate of $0.2 \mu \mathrm{l} / \mathrm{min}$. As a control, 10 additional animals were injected with a similar concentration of the shRandom lentiviral vector. A bare silver wire $(0.1 \mathrm{~mm})$ was affixed to the skull as a ground. The four electrodes were connected to a 4-pin socket and the socket was fixed to the skull with the help of two small screws and dental cement (Gruart et al., 2006). Mice were allowed a week for recovery before the experimental sessions.

Recording and stimulation procedures in the in vivo preparation. Field EPSPs (fEPSPs) were recorded from alert behaving mice with Grass P511 differential amplifiers through a high-impedance probe $\left(2 \times 10^{12} \Omega, 10\right.$ pF). Electrical stimuli presented to Schaffer collaterals consisted of 100 $\mu \mathrm{s}$, square, biphasic pulses presented alone, paired, or in trains. Stimulus intensities ranged from 0.02 to $500 \mu \mathrm{A}$ for the construction of the input/ output curves. For paired-pulse facilitation, the stimulus intensity was set well below the threshold for evoking a population spike, usually $<35 \%$ of the intensity necessary for evoking a maximum fEPSP response (Gureviciene et al., 2004). Paired pulses were presented at six different pulse intervals $(10,20,40,100,200$, and 500). The stimulus intensity was also set at $35 \%$ of its asymptotic value for long-term potentiation (LTP) induction. An additional criterion for selecting stimulus intensity for LTP induction was that a second stimulus, presented $40 \mathrm{~ms}$ after a conditioning pulse, evoked a larger $(>150 \%)$ synaptic field potential than the first (Bliss and Gardner-Medwin, 1973). For LTP induction, each animal was presented with a high-frequency stimulation protocol consisting of five trains $(200 \mathrm{~Hz}, 100 \mathrm{~ms})$ of pulses at a rate of $1 / \mathrm{s}$ as previously described (Gruart et al., 2006).

Statistical analysis. Data are shown as mean \pm SEM of at least three separate experiments. Statistical significance was determined using independent $t$ tests (two-tailed distribution), one-way ANOVA or ANOVA for repeated measures with Bonferroni post hoc multiple-comparisons tests when necessary.

\section{Results \\ Knockdown of NP1 increases the number of excitatory synapses}

We investigated the influence of lentiviral-mediated gain and loss of NP1 expression on synaptic proteins, such as PSD95, a membrane-associated guanylate kinase present at the postsynaptic density of excitatory synapses, and synaptophysin, a presynaptic neurotransmitter vesicle-associated protein (Fig. 1). In characterization experiments, we found that a sequence for RNAi knockdown, shNP1, reduced NP1 overexpression by 70\% (to $30 \pm 4$ of control values; Fig. $1 B$ ) in HEK 293 T cells transiently transfected with pWPI-NP1. In cultured cortical neurons, shNP1 reduced the amount of endogenous NP1 protein by $60-80 \%$ (Figs. 1C,D) to between $39 \pm 9 \%$ (Fig. 1C) and $22 \pm 8 \%$ (Fig. 1D) of control values. Accordingly, we used this shNP1 sequence in 
subsequent experiments to investigate the effects of loss of NP1 expression.

Knockdown of NP1 expression by shNP1 caused a marked increase in PSD95 and synaptophysin protein levels (248 $\pm 14 \%$ and $275 \pm 27 \%$ of control values, respectively; Figs. 1 E, F). Conversely, overexpression of NP1, which increases several fold the amount of NP1 over the level of endogenous protein (Figs. $1 C, D)$, reduced by $\sim 30 \%$ both PSD 95 and synaptophysin protein levels to $77 \pm 24 \%$ and $71 \pm 7 \%$ of controls, respectively, although this effect did not reach statistical significance, probably because of the variability of detection of low amounts of protein with the Western blot technique (Figs. 1E,F).

We next studied whether NP1 overexpression could reverse the increase of synaptic proteins evoked by NP1 knockdown. Transgene overexpression of NP1 with pWPI-NP1 significantly attenuated the increase in both PSD95 and synaptophysin evoked by shNP1 (to $137 \pm 34 \%$ and $186 \pm 15 \%$ of control values, respectively; Figs. $1 E, F$ ). Overexpression of NP1 could not completely reverse these effects of shNP1 because the NP1 transgene is also sensitive to knockdown by shNP1 (Fig. 1C). Thus, to further confirm the specificity of shNP1, we designed a site-mutated form of NP1 (resNP1) containing seven silent mutations at the sequence targeted by shNP1 (Fig. 1A). We found that this resNP1 mutant form of NP1 was insensitive to knockdown by shNP1 both in HEK 293T cells (Fig. 1B) and in cultured cortical neurons (Fig. 1D). Moreover, overexpression of this knockdown-resistant form of NP1 completely blocked the increase in both PSD95 and synaptophysin protein levels caused by shNP1 (Figs. 1E,F), showing that these effects of shNP1 specifically result from knockdown of NP1 expression.

To determine whether the effect of NP1 on synaptic proteins is associated with changes in synaptic contacts, we next performed confocal immunofluorescence studies to assess the number of synaptic puncta in which synaptophysin colocalized with PSD95. In agreement with the results reported in Figure $1 E, F$, knockdown of NP1 caused a marked increase (to $258 \pm 24 \%$ of control) in the number of excitatory synapses as identified by colocalizations between synaptophysin and PSD95 puncta $(0.07 \pm 0.005$ and $0.18 \pm 0.02$ colocalizations per $\mu \mathrm{m}$ of neurite length in shRdm and shNP1, respectively; Figs. $2 A, B$ ). Overexpression of both wild-type and knockdown-resistant forms of NP1 completely blocked this increase in the number of excitatory synapses evoked by shNP1. Moreover, overexpression of either form of NP1 significantly reduced by $\sim 40 \%$ the number of excitatory synapses (from $0.07 \pm 0.005$ to $0.04 \pm 0.006$ and $0.05 \pm 0.006$ colocalizations per $\mu \mathrm{m}$ of neurite length in shRdm, pWPI-NP1, and pWP-resNP1, respectively; Fig. $2 B$, and results not shown).

To determine whether NP1 also affects nonexcitatory synapses, we measured the number of synaptic puncta in which synaptophysin colocalizes with gephyrin, a postsynaptic scaffolding protein associated with inhibitory synapses (Kneussel and Betz, 2000). Knockdown of NP1 did not significantly modify the number of inhibitory synapses (Fig. 2C) or the density of gephyrin puncta $(0.08 \pm 0.03,0.07 \pm 0.02$, and $0.09 \pm 0.02$ gephyrin puncta per $\mu \mathrm{m}$ of neurite length for shRdm/pWPI-C, shNP1/ pWPI-C, and shNP1/pWPI-NP1, respectively; $n=4$ ), suggesting that the effect of NP1 is confined to excitatory synapses.

Excitatory activity is known to stimulate the formation of dendritic spines (Tada and Sheng, 2006). Thus, we hypothesized that the increase in excitatory synapse number caused by shNP1 could be associated with changes in dendritic protrusions. We found that knockdown of NP1 increased by approximately twofold the number of dendritic protrusions $(21.4 \pm 0.5 \mathrm{in}$ shNP1 compared with $9.9 \pm 0.4$ protrusions $/ 50 \mu \mathrm{m}$ neurite length in shRdm control). This effect of NP1 knockdown is specific to NP1 function, because it was completely blocked by the knockdown-resistant form of NP1, resNP1 (Figs. 2D,E). Altogether, these results show that NP1 acts as a limiting factor in the formation of new excitatory, but not inhibitory, synapses and dendritic protrusions.

\section{NP1 knockdown increases $\left[\mathrm{Ca}^{2+}\right]_{\mathrm{i}}$ and the amplitude of spontaneous intracellular $\mathrm{Ca}^{2+}$ oscillations}

To investigate the functional significance of the increase in the number of excitatory synapses caused by NP1 knockdown, we next studied the influence of NP1 on spontaneous intracellular calcium oscillations. Cortical neurons in culture form a synaptic network and show synchronous spontaneous oscillations of the intracellular $\mathrm{Ca}^{2+}$ concentration $\left[\mathrm{Ca}^{2+}\right]_{\mathrm{i}}$ (Fig. 3). These oscillations are synchronized to the burst of action potentials, are due to $\mathrm{Ca}^{2+}$ influx during the spike bursts, and depend on the activation of the AMPA subtype of excitatory amino acid receptors, although they might also be influenced by $\mathrm{Ca}^{2+}$ released from internal stores (Tanaka et al., 1996). Knockdown of NP1 significantly increased basal $\left[\mathrm{Ca}^{2+}\right]_{\mathrm{i}}(94 \pm 2 \mathrm{nM}$ vs $55 \pm 1 \mathrm{nM}$ in shRdm controls). Conversely, overexpression of NP1 caused a small but significant reduction in basal $\left[\mathrm{Ca}^{2+}\right]_{\mathrm{i}}(50 \pm 0.3 \mathrm{nM}$ vs $55 \pm 1 \mathrm{nM}$ in controls; Figs. $3 A, B)$. In addition, NP1 knockdown increased the amplitude of oscillations. Thus, the $\left[\mathrm{Ca}^{2+}\right]_{\mathrm{i}}$ at the peak and bottom of oscillations in cortical neurons treated with shNP1 were significantly higher $(114 \pm 11 / 80 \pm 9 \mathrm{nM})$ than those observed in control neurons treated with shRdm $(64 \pm 5 / 53 \pm 4$ $\mathrm{nM})$ or in neurons overexpressing NP1 (53 $\pm 6 / 47 \pm 6$; Figs. $3 A, B)$. In contrast, knockdown of NP1 did not significantly modify the frequency of the $\left[\mathrm{Ca}^{2+}\right]_{\mathrm{i}}$ oscillations $(0.06 \mathrm{~Hz}$ in neurons treated with shNP1 compared with 0.07 and $0.05 \mathrm{~Hz}$ in NP1-treated neurons and shRdm controls, respectively; Fig. 3B). The sodium channel blocker TTX $(5 \mu \mathrm{M})$ abolished the increase in the $\left[\mathrm{Ca}^{2+}\right]_{\mathrm{i}}$ and spontaneous oscillations evoked by shNP1 (Fig. 3C), indicating that these effects depend on action potentials and synaptic transmission. Both the increase in the $\left[\mathrm{Ca}^{2+}\right]_{\mathrm{i}}$ and spontaneous $\left[\mathrm{Ca}^{2+}\right]_{\mathrm{i}}$ oscillations evoked by the knockdown of NP1 indicate that NP1 negatively regulates excitatory drive, a result that is also consistent with the finding that knockdown of NP1 increases the number of excitatory synapses.

\section{Knockdown of NP1 recruits GluA1 and GluN1 to new excitatory synapses}

We next examined whether the increase in the number of excitatory synapses evoked by the knockdown of NP1 is related to changes in the levels of excitatory amino acid receptors at the cell surface. Biotinylation assays to measure the amount of excitatory neurotransmitter receptors at the cell surface of cultured cortical neurons revealed that knockdown of NP1 did not modify the total or surface levels of the GluA1 and GluA2 AMPA receptor subunits or of the GluN1 subunit of NMDA receptors. Surface (biotinylated/total) GluA1, GluA2, and GluN1 receptors after NP1 knockdown were as follows: $117 \pm 20 \%(n=8), 96 \pm 11 \%$ $(n=9)$, and $86 \pm 12 \%(n=8)$ of control shRdm values, respectively. In contrast, double-immunostaining of cultured cortical cells revealed that knockdown of NP1 markedly increased to $\sim 368 \%$ of control the number of surface GluA1 puncta that colocalized with the excitatory presynaptic marker vesicular glutamate transporter-1 (VGLUT1; $0.11 \pm 0.02$ vs $0.03 \pm 0.01$ colocalizations/ $\mu \mathrm{m}$ neurite length in shNP1 and shRdm control, respectively; Fig. 4A). A similar increase to $260 \%$ of control was observed in the number of VGLUT1 and GluN1 colocalizations 
A

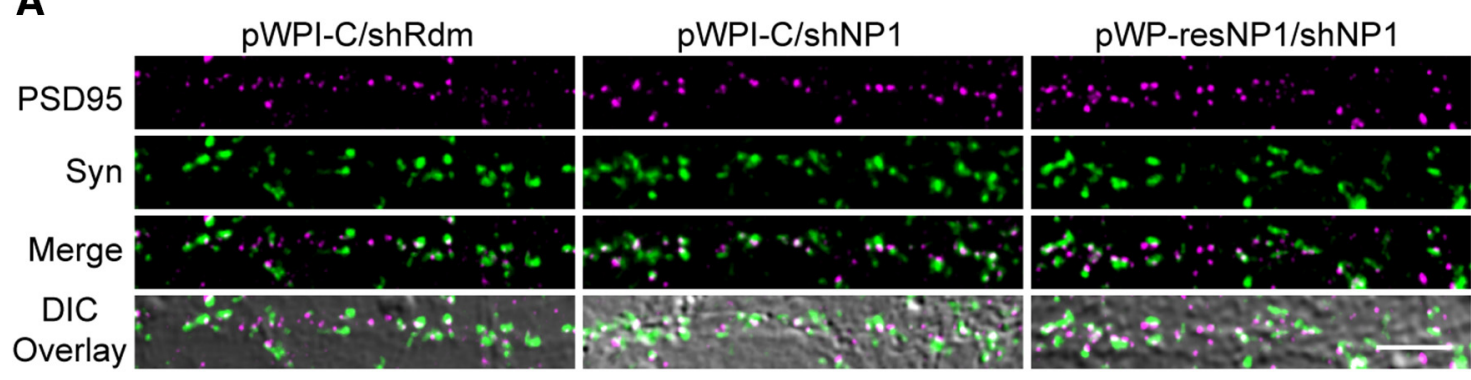

B

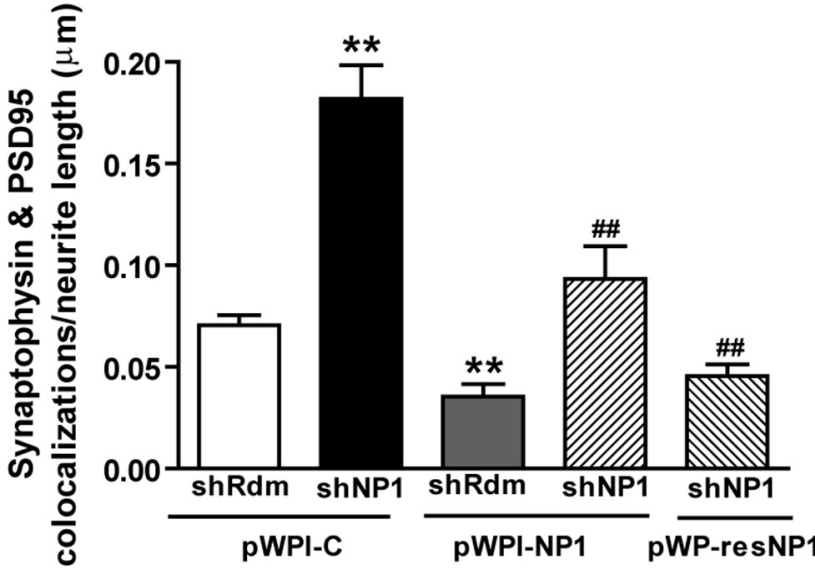

C

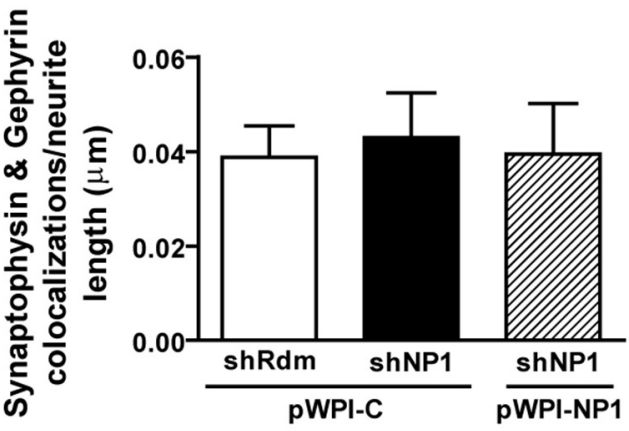

D
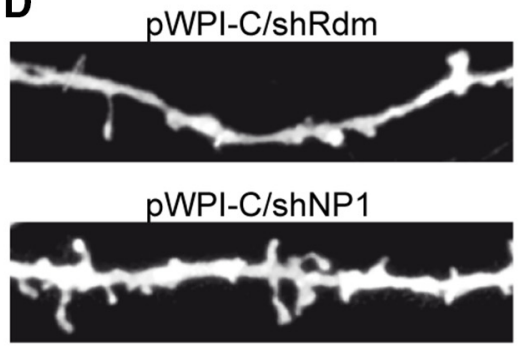

pWP-resNP1/shNP1

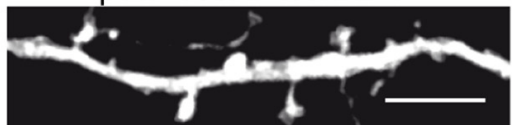

E

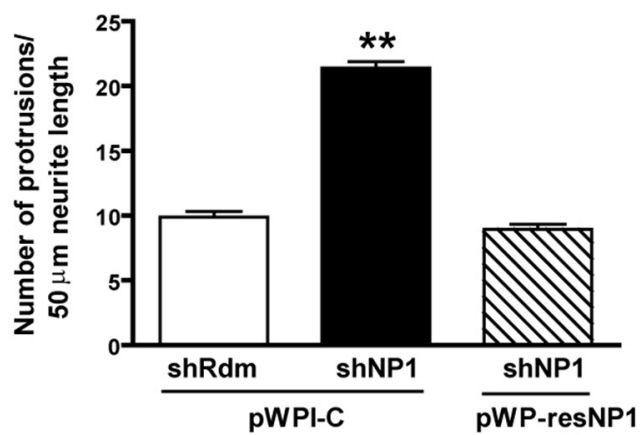

Figure 2. Knockdown of NP1 increases the number of excitatory synapses and dendritic protrusions in primary cultures of cortical neurons. NP1 expression was silenced by lentiviral-mediated transduction of shNP1. Rescue experiments were performed by transgene overexpression of either a wild-type (pWPI-NP1) or a resistant to knockdown (pWP-resNP1) form of NP1. Values are mean \pm SEM of $n$ independent experiments. $A$, Representative images of PSD95 (magenta) and synaptophysin (Syn; green) colocalizations (white) overlaid onto the corresponding DIC image. Scale bar, $5 \mu \mathrm{m}$. $\boldsymbol{B}$, Quantitative analysis of the number of PSD95 and synaptophysin colocalizations per neurite length in the immunocytochemical experiments represented in $A$. The total number of fields $(f)$ analyzed per $n$ independent experiments are as follows: shRdm/pWPI-C, $f=61, n=7 ; \operatorname{shNP1/pWPI-C,~} f=48 n=5 ;$ shRdm/pWPI-NP1, $f=23, n=3 ;$ shNP1/pWPI-NP1, $f=24, n=$ 3 ; shNP1/pWPI-resNP1, $f=24, n=3$. C, Quantitative analysis of the number of gephyrin and synaptophysin colocalizations per neurite length (shRdm/pWPI-C, $f=23 ;$ shNP1/pWPI-C, $f=24$; shNP1/pWPI-NP1, $f=18 ;$ ANOVA, $p=0.93, n=3)$. D, Representative images of dendrites from cultured cortical neurons analyzed for the density of dendritic protrusions, including both spines and filopodia. Scale bar, $5 \mu \mathrm{m}$. $E$, Quantitative analysis of number of protrusions per neurite length. The number of neurites and independent experiments for each treatment are as follows: shRdm/pWPI-C $=26, n=4 ;$ shNP1/pWPI-C $=26, n=4 ;$ shNP1/pWP-resNP1 $=16, n=2$ (** significantly different from shRdm/pWPI-C; $p<0.01$; \#significantly different from shNP1/pWPI-C; $\# p<0.05$,\#\#p $<0.01$, Bonferroni post hoc tests).

$(0.08 \pm 0.01$ vs $0.03 \pm 0.01$ colocalizations $/ \mu \mathrm{m}$ neurite length in shNP1 and shRdm control, respectively; Fig. $4 B$ ). Overall, these results indicate that regulation of synapse number by NP1 is associated with the recruitment and relocalization of extrasynaptic amino acid receptors to new synapses.

Previous reports suggest that NP1 binds and regulates the clustering of AMPA-subtype glutamate receptors at excitatory synapses in specific subsets of neurons (Xu et al., 2003; Sia et al., 2007). Therefore, knockdown of NP1 might also modify the effi- cacy of excitatory synapses in addition to increasing their number. To explore this possibility, we measured miniature EPSCs (mEPSCs). Knockdown of NP1 significantly increased the frequency of excitatory mEPSCs, but did not modify their amplitude (Figs. $4 C-G$ ). Changes in mEPSCs amplitude are generally attributed to changes in postsynaptic excitatory amino acid receptor conductance or number (with the latter being also associated with the conversion of silent to functional synapses), whereas changes in mEPSCs frequency are considered to reflect 
A

\section{shRdm}

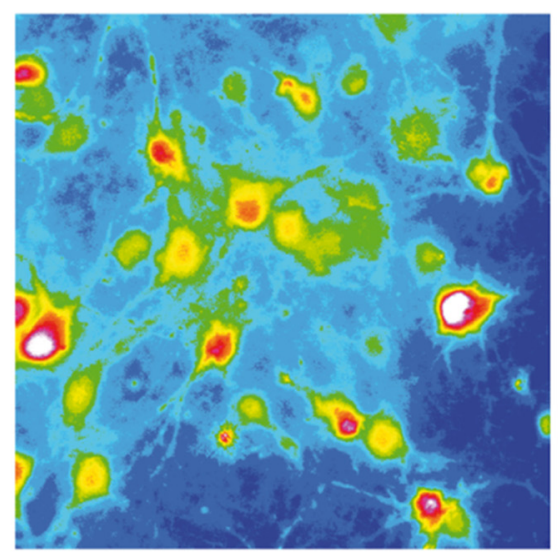

pWPI-NP1

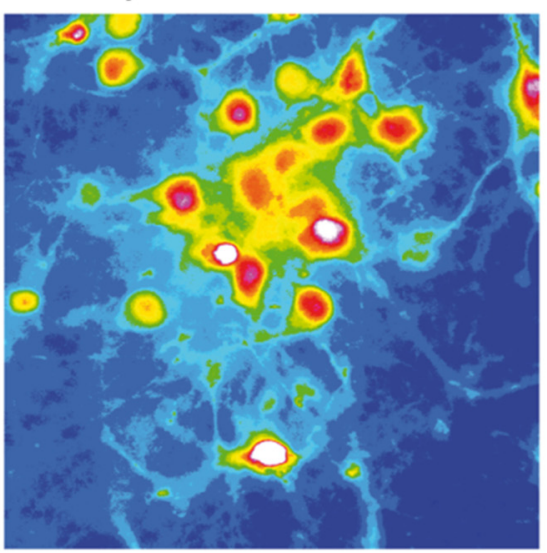

shNP1

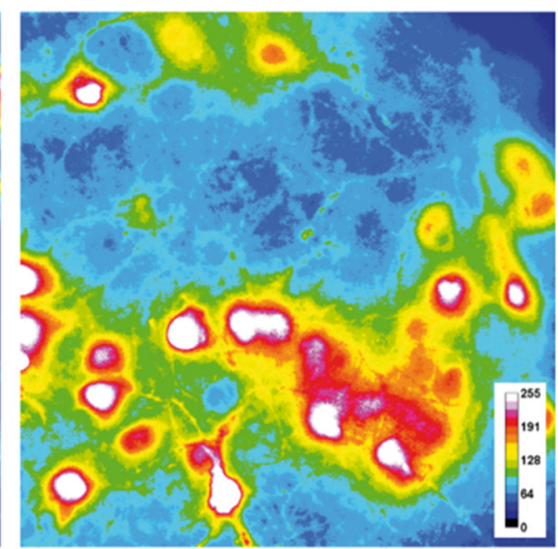

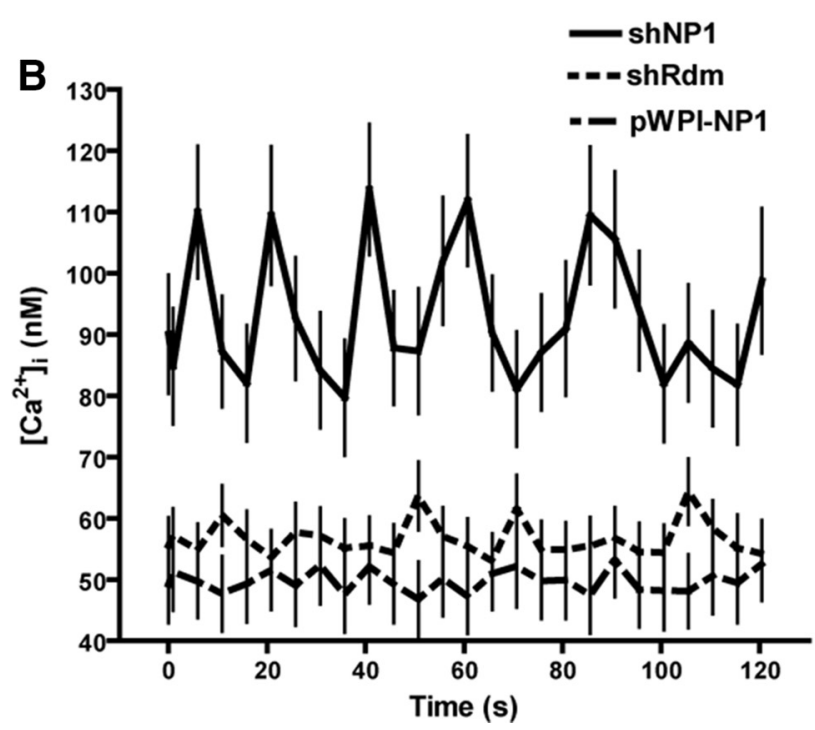

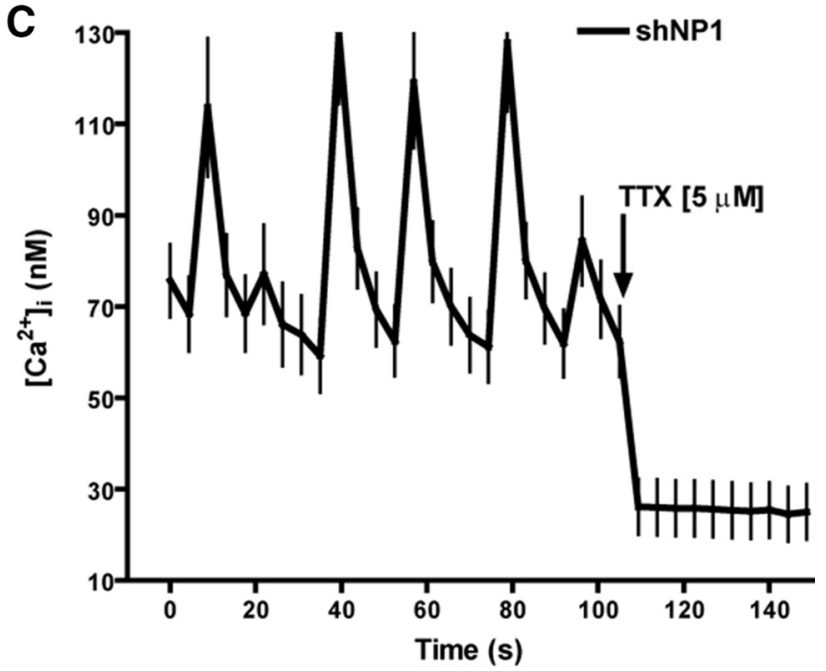

Figure 3. NP1 knockdown increases $\left[\mathrm{Ca}^{2+}\right]_{i}$ and the amplitude of spontaneous intracellular $\mathrm{Ca}^{2+}$ oscillations. Cortical cultured neurons were transduced with shNP1 to knockdown NP1 expression, with pWPI-NP1 to overexpress NP1, or with shRdm as control. $\boldsymbol{A}-\boldsymbol{C}$, Intracellular $\mathrm{Ca}^{2+}$ concentration was measured in the soma of mature neurons with Fura-2.A, Representative images of Fura- 2 fluorescence pseudo-colored according to intensity in cortical cell cultures after gain and loss of NP1 function. $B$, Spontaneous $\left[\mathrm{Ca}^{2+}\right]_{i}$ oscillations. Values are mean \pm SEM of 52 neurons for shRdm (dotted line), 52 neurons for shNP1 (solid line), and 36 neurons for pWPI-NP1 (dashed line) from at least $n=4$ independent cultures. Mean [Ca $\left.{ }^{2+}\right]_{i}$ of shNP1 is significantly higher than pWPI-NP1 and shRdm ( $p<0.001$, independent $t$ test). NP1 knockdown significantly increased the amplitude of $\left[\mathrm{Ca}^{2+}\right]_{\mathrm{i}}$ oscillations compared with control or NP1 overexpressing neurons ( $p<$ 0.001 , independent $t$ test). NP1 overexpression significantly reduced basal $\left[\mathrm{Ca}^{2+}\right]_{\mathrm{i}} \mathrm{C}$, Spontaneous $\left[\mathrm{Ca}^{2+}\right]_{\mathrm{i}}$ oscillations induced by knockdown of NP1 are abolished after addition of TTX (5 $\mu \mathrm{M} ; 23$ neurons).

both the probability of vesicle release from the presynaptic terminal and the number of synapses (Kerchner and Nicoll, 2008). Thus, these findings are consistent with the interpretation that the increase in excitatory drive caused by knockdown of NP1 is due to an increase in the number, but not the efficacy, of excitatory synapses, although this does exclude the possibility that changes in release probability are also involved.

\section{NP1 interacts with Kv7.2 and coimmunoprecipitates syntaxin $1 \mathrm{~A}$}

Next, we performed a proteomic study to identify proteins binding NP1 that are involved in the regulation of neuronal excitability and that could explain the synaptic effects of NP1. The analysis of proteins bound to NP1 in native conditions revealed that, in addition to the previously reported interaction of NP1 with AMPA receptor subunits (Xu et al., 2003), the Kv7.2 subunit of the voltage-gated KCNQ family of potassium channels interacts with NP1 (Fig. 5). The Kv7.2 subunit, together with the Kv7.3 subunit of the Kv7 channel family, forms a potassium channel that underlies the M-current, a slowly activating and deactivating potassium conductance, which determines the subthreshold electrical excitability of neurons, as well as the responsiveness to synaptic inputs (Wang et al., 1998; Brown, 2008). We performed a number of experiments to verify the interaction of NP1 with the Kv7.2 subunit of potassium channels. First, coimmunoprecipitation studies using rat brain tissue confirmed that endogenous $\mathrm{NP1}$ and Kv7.2 proteins interact in native conditions (Fig. 5A). In contrast, NP1 does not coimmunoprecipitate endogenous Kv7.3 protein (Fig. 5A), indicating that NP1 selectively interacts with only one type of Kv7 channel subunit. Previous studies have shown that Kv7.2, but not Kv7.3, subunits of Kv7 channels interact with syntaxin 1A (Regev et al., 2009). Following on this finding, and to study the interaction between endogenous NP1 and Kv7.2 proteins, we examined whether NP1 interacts with syntaxin 1A. The results confirmed that NP1 coimmunoprecipitates a complex of Kv7.2 and syntaxin 1A proteins (Fig. 5A). Recipro- 
A

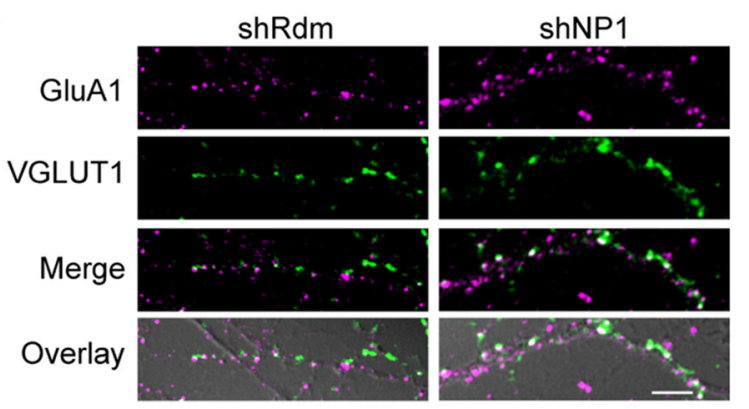

B

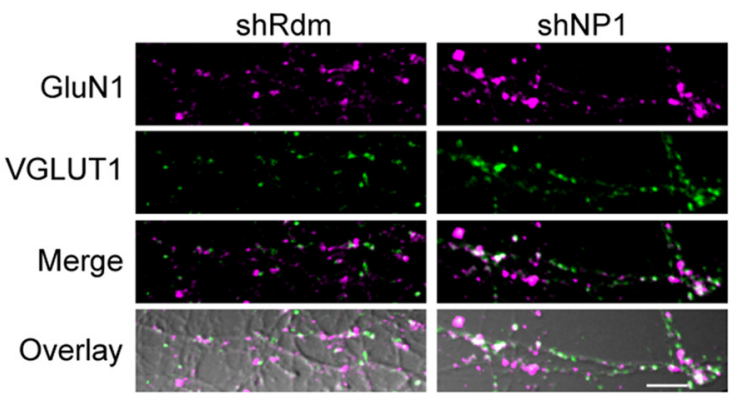

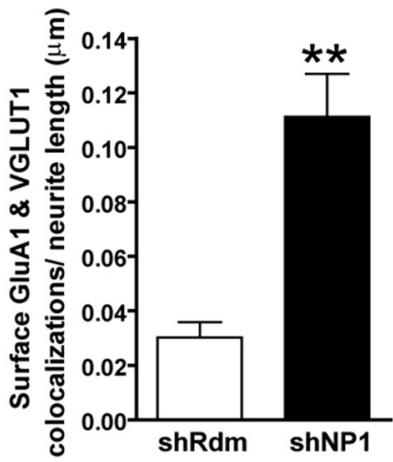

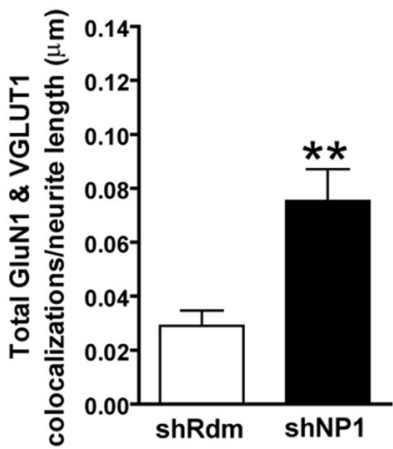

C

shRdm

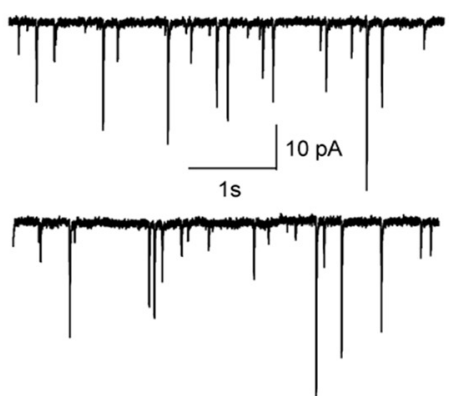

shNP1

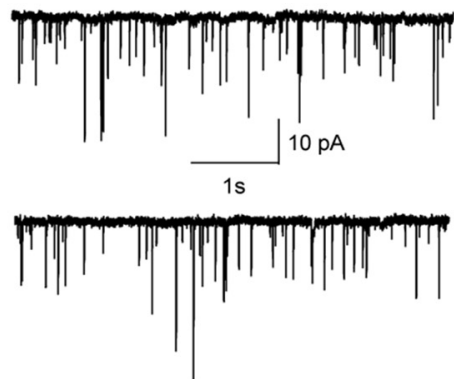

D

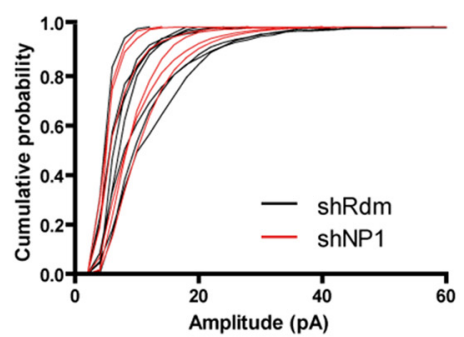

F

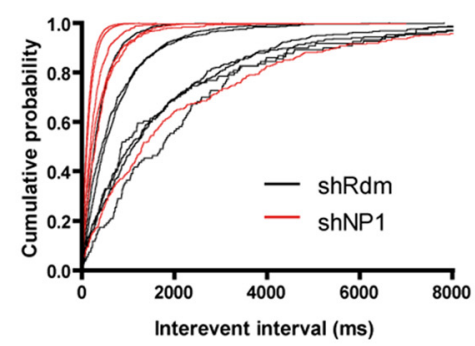

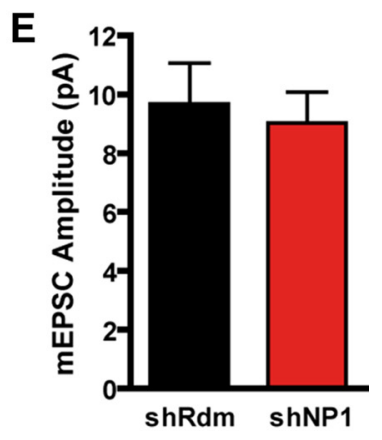

G

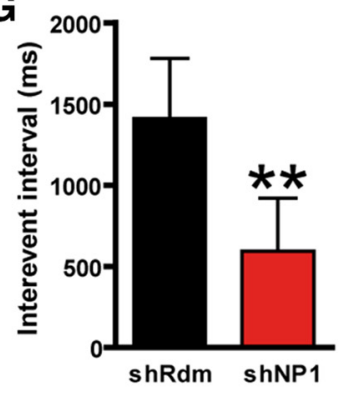

Figure 4. Knockdown of NP1 recruits GluA1 and GluN1 to new excitatory synapses and increases the frequency of excitatory mEPSCs. $\boldsymbol{A}, \boldsymbol{B}$, Representative confocal images and quantitative analysis of colocalizations of VGLUT1 with surface GluA1 $(\boldsymbol{A})$ or total GluN1 receptors ( $\boldsymbol{B})$. White indicates colocalization of GluA1 or GluN1 (magenta) and VGLUT1 (green). These are overlaid onto the corresponding DIC image to show sites of colocalization within a neurite. Scale bar, $5 \mu \mathrm{m}$. Studies were performed in mature cultured cortical neurons. GluA1 and GluN1 immunostaining were performed in live and fixed neurons, respectively. Values are mean \pm SEM of the number of colocalizations per $\mu \mathrm{m}$ of neurite length ( 29 neurons in each group for $\mathrm{GluA} 1(\boldsymbol{A})$ and 23 neurons in each group for GluN1 (B), from $n=3$ independent experiments). C, Representative traces from spontaneous mEPSC recordings from shRdm (top) and NP1-silenced neurons (bottom). Neurons were held at $-70 \mathrm{mV}$ and $\mathrm{mEPSC}$ were recorded in the presence of $2 \mu \mathrm{m} \mathrm{TTX}, 10 \mu \mathrm{m}$ picrotoxin, and $10 \mu \mathrm{m}$ bicuculline. $\boldsymbol{D}$, Cumulative probability plots of mEPSC amplitude. E, Mean \pm SEM of mEPSC amplitude in shRdm $(n=7)$ and shNP1 $(n=6) . F$, Cumulative probability plots of mEPSC frequency. G, Mean \pm SEM of mEPSC interevent interval in control shRdm $(n=7)$ and shNP1 knockdown neurons ( $n=6$; ${ }^{* *}$ significantly different from shRdm; $p<0.01$, Student's $t$ test, two-tailed). 
A

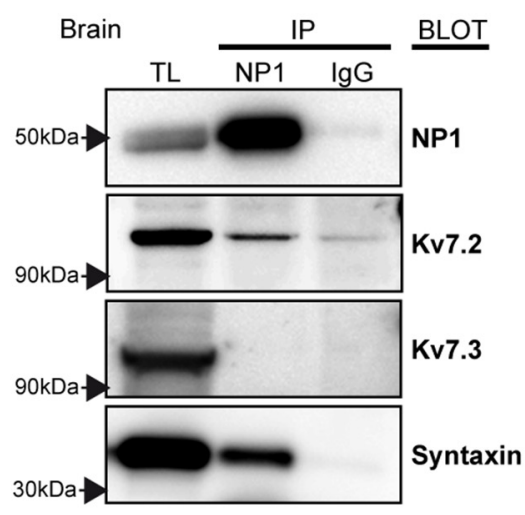

C

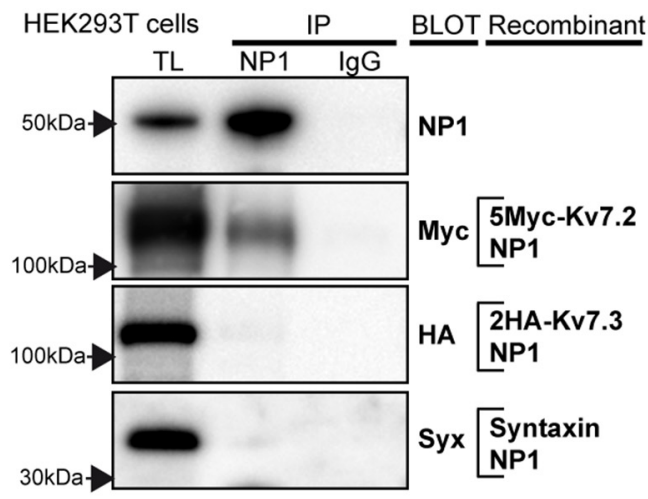

E

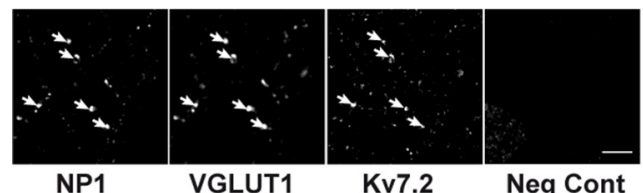

Merge

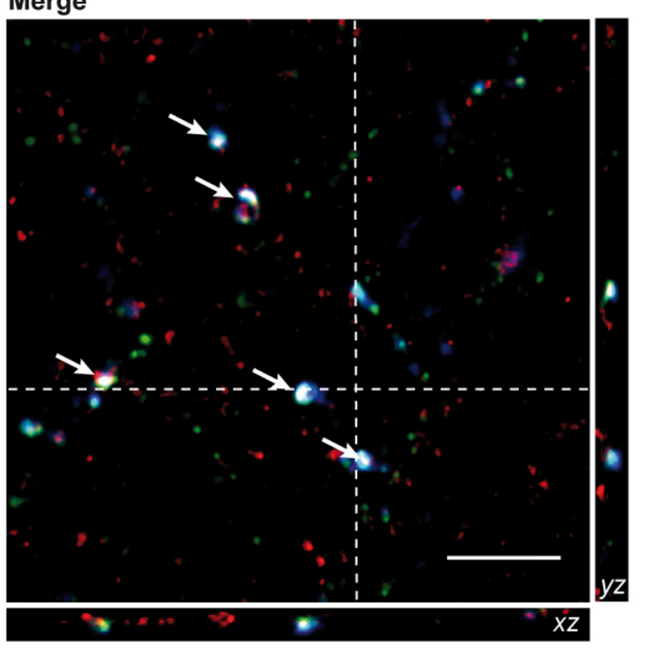

B

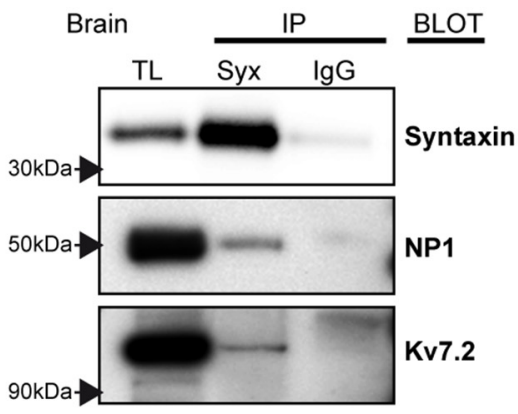

D

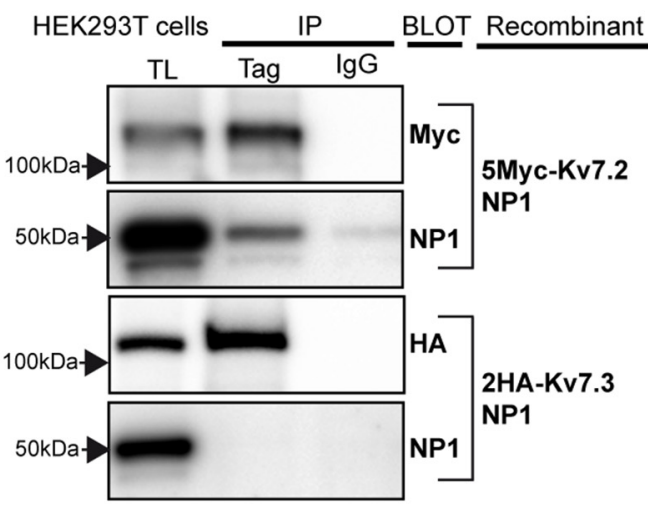

$\mathbf{F}$
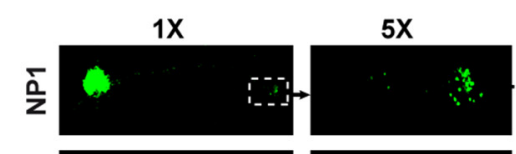

Neg Cont 5X
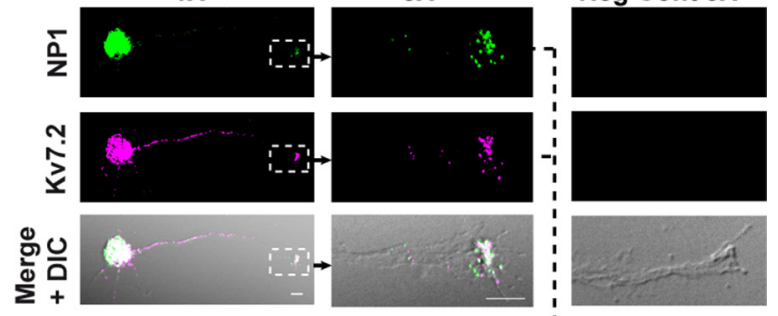
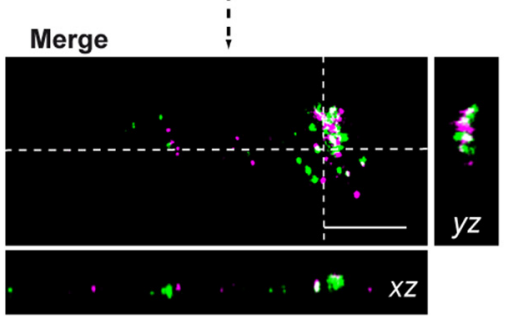

Figure 5. NP1 interacts and colocalizes with Kv7.2 at presynaptic terminals of excitatory synapses and axonal growth cones. $\boldsymbol{A}-\boldsymbol{D}$, Representative Western blots of immunoprecipitation eluates separated in 6\% Tris-Glycine (for high molecular weight proteins) and 4-12\% Bis-Tris gels (for low molecular weight proteins). TL, Total protein lysate; Syx, syntaxin. $\boldsymbol{A}$, Both native Kv7.2 and syntaxin 1A, but not Kv7.3, coprecipitate with NP1 in total brain extracts. B, Both native Kv7.2 and NP1 coprecipitate with syntaxin in total brain extracts. C, D, Recombinant NP1 coprecipitates Kv7.2, but not syntaxin or Kv7.3, in 293T cells transfected with NP1, 5Myc-Kv7.2, 2HA-Kv7.3, and syntaxin 1A cDNAs. Kv7.2 and Kv7.3 were immunoprecipitated with antibodies against their respective Myc and HA tags. $\boldsymbol{E}, \boldsymbol{F}$, Immunofluorescence studies and confocal microscopy were performed in high-density $(\boldsymbol{E})$ or low-density $(\boldsymbol{F})$ isolated cortical neurons. $\boldsymbol{E}$, Top, Confocal sections of $0.772 \mu$ m in the z-plane showing immunofluorescence of NP1, VGLUT1, Kv7.2, and negative control (omitting primary antibodies). Bottom, Colocalization (in white) of the excitatory (Figure legend continues.) 
cal immunoprecipitation experiments further confirmed that endogenous syntaxin 1A coimmunoprecipitates both NP1 and Kv7.2 (Fig. 5B). To further examine the interaction between NP1, Kv7.2, and syntaxin 1A we performed reciprocal coimmunoprecipitation studies with the recombinant subunits 5Myc-KCNQ2, 2HA-KCNQ3, and syntaxin 1A expressed together with recombinant NP1 in HEK 293T cells. In these cells, we confirmed that NP1 coimmunoprecipitates the Kv7.2 subunit of Kv7 channels but does not interact with either Kv7.3 or syntaxin 1A (Figs. $5 C, D)$, suggesting a direct interaction between NP1 and Kv7.2 proteins and indicating that NP1 immunoprecipitates syntaxin 1A through an indirect interaction with Kv7.2 (Figs. 5C,D).

\section{NP1 colocalizes with Kv7.2 in presynaptic terminals of excitatory synapses and in growth cones}

To further investigate the interaction between NP1 and Kv7.2 and its relationship with synapses in cultured cortical neurons, we performed triple-labeling immunofluorescence experiments and analysis by confocal microscopy (Figs. $5 E, F$ ). The specificity of Kv7.2 immunofluorescence was tested by preabsorption of the antibody (results not shown). As previously reported (Cooper et al., 2001; Devaux et al., 2004; Regev et al., 2009), Kv7.2 expression was widespread and was found at axon initial segments and axon terminal sites (Fig. 5E, and data not shown) where it partially colocalized with NP1. To label the presynaptic compartment of excitatory synapses we used an antibody against the vesicular glutamate transporter VGLUT1. Orthogonal sections of confocal images showed that Kv7.2 and NP1 colocalize with VGLUT1 (Fig. 5E), indicating that NP1 and Kv7.2 can be found at presynaptic compartments. This observation, together with the finding that NP1 coimmunoprecipitates Kv7.2 and syntaxin 1, indicates that NP1 and Kv7.2 interact at the presynaptic side of excitatory synapses. In agreement with these observations, we found that NP1 and Kv7.2 are both present and colocalize in axonal growth cones of isolated immature cortical neurons (Fig. $5 F$ ).

\section{Knockdown of NP1 reduces Kv7/M-current}

Following on the finding of the interaction between NP1 and Kv7.2, we next asked whether modulation of NP1 expression would modify the Kv7/M-current. First, we performed biotinylation assays to measure the amount of Kv7.2 protein at the neuronal cell surface (Figs. 6A,B). Knockdown of NP1 expression significantly decreased (to $66 \pm 6 \%$ of control values) the amount of Kv7.2 at the neuronal surface of cultured cortical cells (Fig. $6 B)$. In contrast, overexpression of NP1 caused a small, but significant, increase in the amount of Kv7.2 protein at the neuronal surface (to $118 \pm 6 \%$ of control values; Fig. $6 B$ ). Because changes in the amount of Kv7.2 protein at the cell surface may in turn modify Kv7 channel activity, we performed whole-cell voltage-

$\leftarrow$

(Figure legend continued.) presynaptic marker VGLUT1 (blue) with NP1 (green) and Kv7.2 (red) is shown in a single section with the corresponding orthogonal views of the stack of confocal sections. White arrows indicate sites of colocalization. $\boldsymbol{F}$, NP1 (green) and KV7.2 (magenta) immunofluorescence and DIC images of an isolated cortical cultured neuron $(1 X)$ with its corresponding axonal growth cone highlighted in a white square box, shown in a confocal section of $0.772 \mu \mathrm{m}$ in the $z$-plane at higher $(5 \times)$ magnification. The negative control for primary antibodies is shown in another growth cone on the right. The image in the bottom is the merge of NP1 and Kv7.2 immunofluorescence images in the single confocal section obtained at $5 \times$ showing colocalization (white) of NP1 and Kv7.2 in the growth cone, with the corresponding orthogonal views from its respective stack of confocal sections. Images were acquired using restricted spectral emission wavelength ranges chosen to avoid crosstalk or bleed-through between the three different channels. Scale bar, $5 \mu \mathrm{m}$. clamp experiments to record the M-current (Fig. 6C). These experiments revealed that knockdown of NP1 significantly decreased the M-type $\mathrm{K}^{+}$current $(0.88 \pm 0.15$ in shNP1 vs $2.19 \pm 0.33 \mathrm{pA} / \mathrm{pF}$ in shRdm control; Figs. $6 C, D)$. The specificity of the effect of shNP1 on the M-current was further confirmed in rescue control experiments with the knockdown-resistant form of NP1, which completely prevented the reduction in the M-current evoked by shNP1 (Figs. 6C, D). In contrast, knockdown of NP1 did not modify the A-type potassium current (Fig. $6 E)$, a fast activating-inactivating outward potassium current subserved by a different family of voltage-gated potassium channels that also regulate neuronal excitability (Yuan and Chen, 2006). Moreover, current-clamp experiments revealed that NP1 knockdown facilitates repetitive spike discharges after depolarization (Fig. $7 A, B$ ), an effect that is equivalent to that observed after blockade of Kv7.2 channels (Brown and Passmore, 2009). We checked whether the effect of NP1 knockdown on neuronal excitability depends on neuronal transmission and we found that blockade of synaptic transmission does not prevent the increase in neuronal excitability evoked by knockdown of NP1 (shRdm: $3.9 \pm 1.2$ spikes, $n=7$; shNPI: $15.0 \pm 3.1$ spikes, $n=7$; Fig. $7 C$ ). In addition, to test whether the increase in neuronal excitability evoked by shNP1 could be due to a reduction of calciumactivated potassium channel currents rather than M-current we measured fast AHP after inducing neuronal firing with shortdepolarizing pulses $(2 \mathrm{~ms})$. We found that treatment of cultured cortical neurons with shNP1 does not significantly modify AHP (shRdm: $-4.36 \pm 0.8 \mathrm{mV}, n=7$; shNPI: $-3.71 \pm 1.0 \mathrm{mV}, n=$ $7)$. We also measured slow AHP elicited by depolarizing pulses of longer duration ( $100 \mathrm{~ms}, 250 \mathrm{pA}$ and $1 \mathrm{~s}, 50 \mathrm{pA})$. This late form of AHP is thought to be mediated by a group of potassium channels indirectly activated by calcium, including Kv7 channels (for review, see Andrade et al., 2012). We found that treatment of cultured cortical neurons with shNP1 slightly reduced sAHP elicited by the two types of pulses, but this effect did not reach statistical significance (100 ms pulse: shRdm: $-4.98 \pm 0.26 \mathrm{mV}, n=5$; shNPI: $-3.47 \pm 0.80 \mathrm{mV}, n=6 ; 1 \mathrm{~s}$ pulse: shRdm: $-3.21 \pm 0.83$ $\mathrm{mV}, n=9$; shNPI: $-2.32 \pm 0.81 \mathrm{mV}, n=7$; Student's $t$ test, $p>$ $0.1)$. Nonetheless, the observation that the amplitude of sAHP elicited by NP1 knockdown was slightly smaller than the observed in controls is consistent with the reduction of surface levels of Kv7.2 evoked by NP1 and with previous results showing that these channels partially contribute to SAHP (Tzingounis and Nicoll, 2008). Overall, the decrease in the M-type potassium current caused by knockdown of NP1 is consistent with the reduction in the surface levels of Kv7.2 observed after the same treatment and suggests that modulation of the M-current may be one of the mechanisms by which NP1 regulates neuronal excitability.

\section{Pharmacological activation of Kv7 channels prevents the increase in synaptic proteins caused by NP1 knockdown}

We next asked whether the increase in excitatory synapses and the reduction of the M-current caused by the knockdown of NP1 are parallel processes or if one depends on the other. To address this question, we investigated whether changes in Kv7 channel activity play a role in the upregulation of synaptic proteins evoked by NP1 knockdown. Treatment of cultured cortical neurons with linopirdine, an inhibitor of the M-current (Lamas et al., 1997), caused a concentration-dependent increase in both synaptophy$\sin (E \max =217 \pm 24 \%$ of control $)$ and PSD95 $($ Emax $=222 \pm$ $40 \%$ of control) protein levels (Fig. $8 A$ ) that was similar to that observed after knockdown of NP1 (Figs. $1 F, G$ ). Interestingly, the potency of linopirdine to increase synaptophysin $\left(\mathrm{EC}_{50}=0.09\right.$ 
A

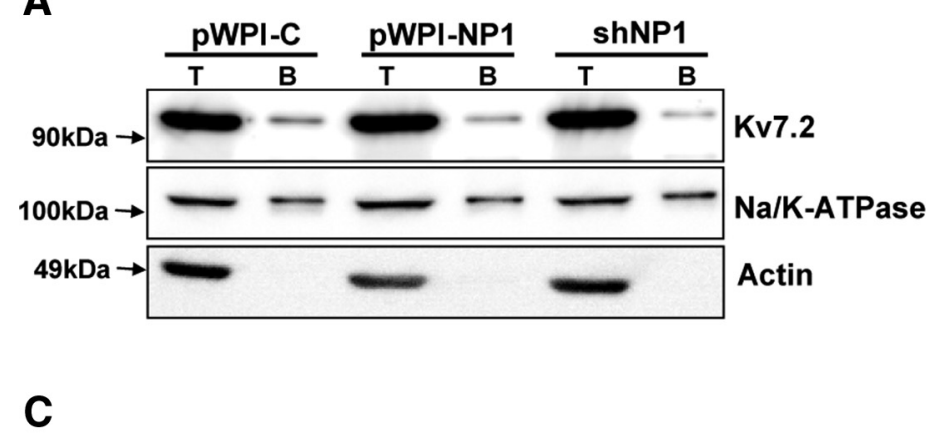

B

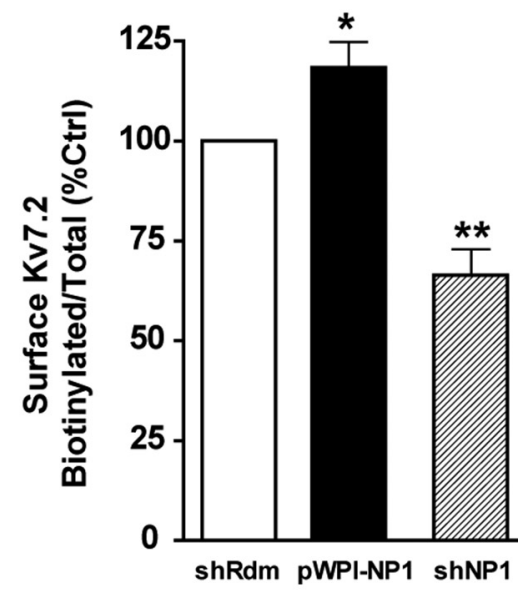

D

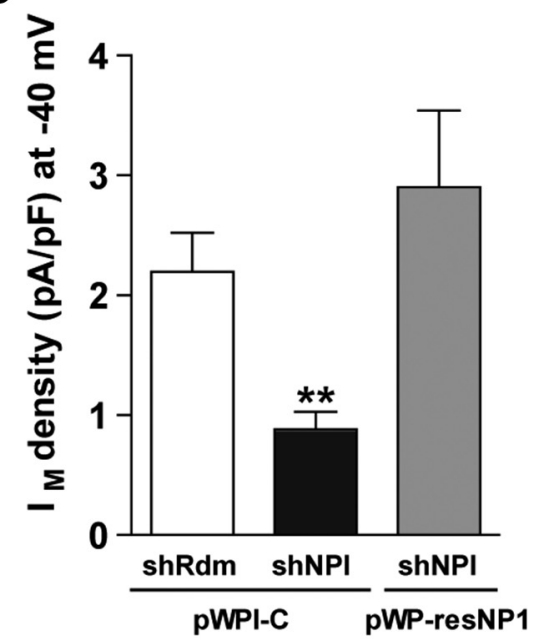

$\mathbf{E}$
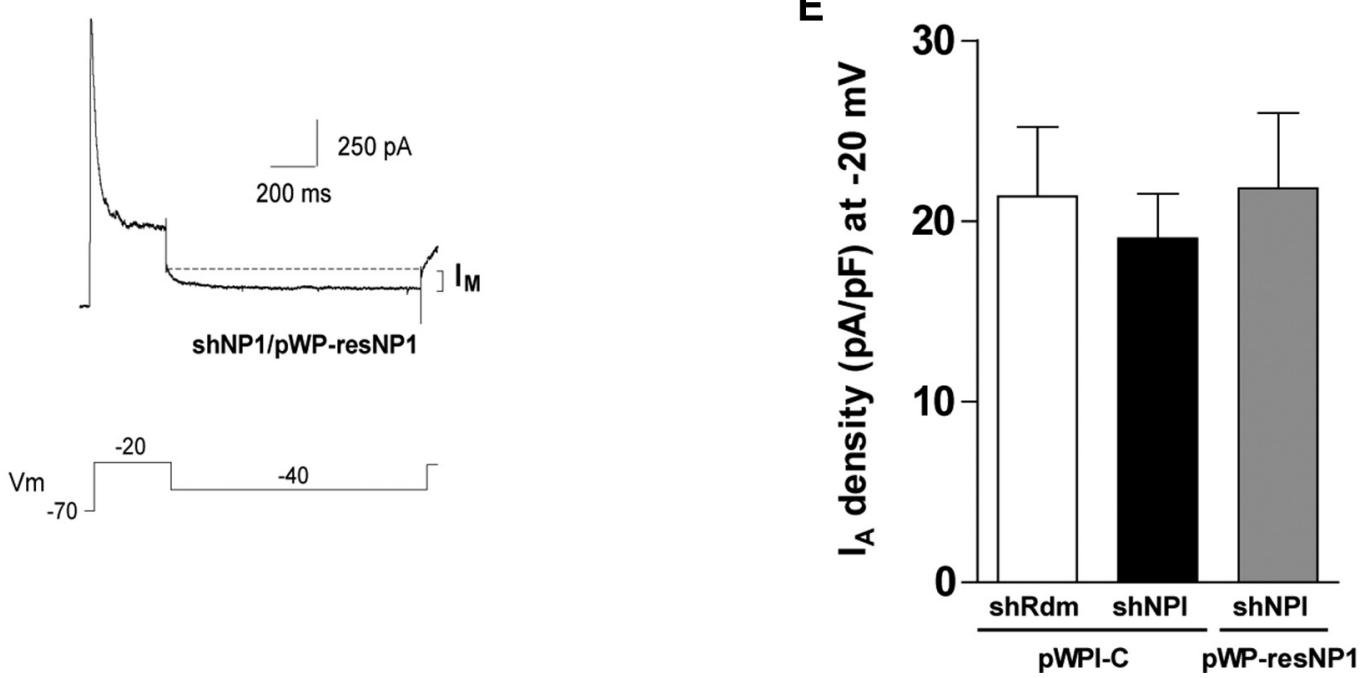

Figure 6. Knockdown ofNP1 reduces Kv7.2surface expression andM-current. $A, B$, The proportion ofKv7.2 at theneuronal surface was determined by biotinylation $\left(30\right.$ min at $\left.4^{\circ} \mathrm{C}\right)$ of all surfaceproteins in cultured cortical neurons. The ratio of the surface over the total amount of receptor was determined by densitometric analysis and expressed as a percentage of control values. Only samples of biotinylated proteins lacking immunoreactivity to actin, which indicates contamination with intracellular proteins, were used for analyses. $\boldsymbol{A}$, Representative Western blots of Kv7.2, Na-KATPase, and actin from total (T) and biotinylated (B) proteins. B, Quantitative analysis of the effect of gain and loss of NP1 on the surface/total levels of the Kv7.2 subunit of the voltage-gated Kv7/MK ${ }^{+}$channels. Values are mean \pm SEM of shRdm $(n=11)$, shNP1 $(n=11)$, and pWPI-NP1 ( $\left.n=5\right)$, from at least three independent experiments; ${ }^{*} p<0.05,{ }^{* *} p<0.01$, two-tailed, dependent $t$ tests. C, Representative recordings from cortical cells treated with shRdm/pWPI-control (top), shNP1/pWPI-control (middle), and shNP1/ pWP-resNP1 (bottom). From a holding voltage of $-70 \mathrm{mV}$, outward currents were activated by a $400 \mathrm{~ms}$ depolarizing pulse to $-20 \mathrm{mV}$ followed by a 1 shyperpolarizing pulseto $-40 \mathrm{mV}$ to deactivatethe M-current. Peak A-current amplitude was measured from the initial $-20 \mathrm{mV}$ pulse. Deactivating M-current amplitude was measured at $-40 \mathrm{mV} . \mathbf{D}, E, \mathrm{M}$ - and A-current densities (pA/pF) obtained in shRdm/pWPI-C (white, $n=17)$, shNP1/pWPI-C (black, $n=20)$, and shNP1/pWP-resNP1 (gray; $n=16$, mean \pm SEM; ${ }^{* *} p<0.01$, two-tailed independent $t$ testvs shRdm). To avoid underestimation of thefast A-type current peakmeasurement, wealso obtained peak A-current amplitude from the extrapolated single exponential fitting line to the inactivation phase and observed similar results. 
A

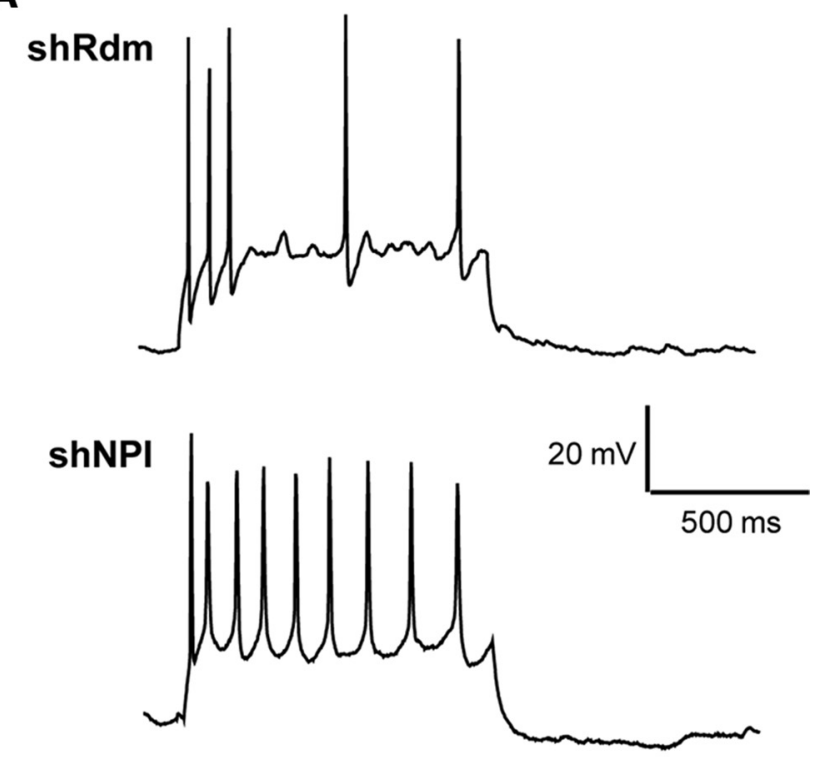

Current at Th

B

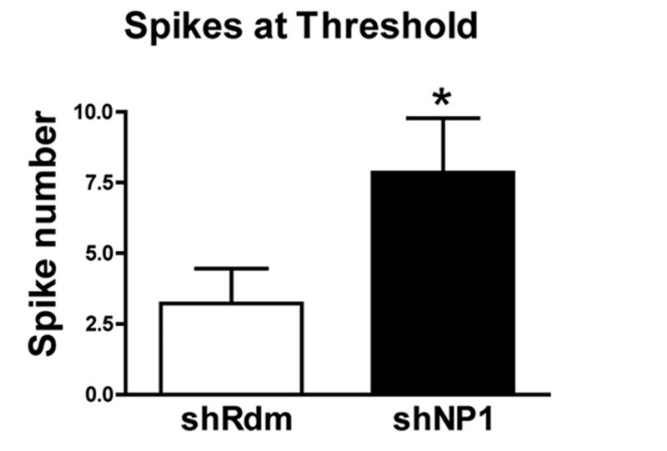

C
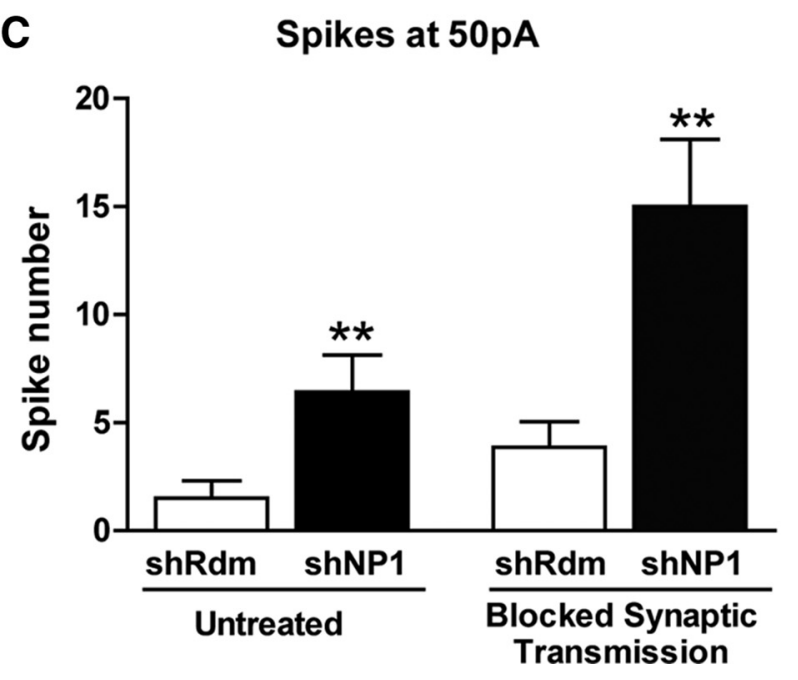

Figure 7. Knockdown of NP1 increases neuronal excitability. $A$, Current-clamp recordings of membrane voltage were used to study neuronal excitability in cultured cortical neurons treated with shRdm as control $(n=9)$ and shNP1 to knockdown NP1 $(n=7)$. Repetitive discharge was measured by counting the spikes evoked by $1 \mathrm{~s}$ intracellular depolarizing current pulse at threshold current $(\boldsymbol{B})$ or at $+50 \mathrm{pA}$ in the absence or presence of $20 \mu \mathrm{m}$ bicuculine, $20 \mu \mathrm{M} C \mathrm{NQX}$, and $100 \mu \mathrm{m}$ AP7 to block synaptic transmission (C); ${ }^{*} p<0.05$, ${ }^{* *} p<0.01$; two-tailed independent $t$ test vs shRdm. $\mu \mathrm{M})$ was markedly higher than its potency to increase PSD95 protein levels $\left(\mathrm{EC}_{50}=1.5 \mu \mathrm{M}\right)$, which suggests that regulation of synaptophysin levels precedes that of PSD95 (Fig. 8A). To determine whether the effect of linopirdine on synaptic proteins is also associated with changes in synaptic contacts, we performed additional confocal immunofluorescence studies. As expected, treatment of cortical cultured neurons with $1 \mu \mathrm{M}$ linopirdine caused a marked increase (to $275 \pm 26 \%$ of control) in the number of excitatory synapses as identified by colocalizations between synaptophysin and PSD95 puncta $(0.04 \pm 0.01$ and $0.11 \pm 0.01$ colocalizations per $\mu \mathrm{m}$ of neurite length in vehicle and linopirdine treated neurons, respectively; Fig. $8 B$ ). We next examined whether the synaptic effects of NP1 knockdown could be antagonized by enhancing Kv7 channel function. Flupirtine, a Kv7 channel opener (Martire et al., 2004), blocked the increase in both synaptophysin and PSD95 proteins caused by the knockdown of NP1 (Fig. 8C), providing further evidence that NP1 regulates the number of excitatory synapses through modulation of Kv7 channel activity.

Influence of excitatory neurotransmission on the increase in synaptic proteins evoked by NP1 knockdown

To gain further insight into the molecular mechanisms mediating the increase in excitatory synapses evoked by shNP1, we studied the influence of TTX (which prevents evoked, but not spontaneous, glutamate release) and CNQX (an AMPA receptor antagonist) on this effect. We found that chronic treatment with either TTX $(2 \mu \mathrm{M})$ or CNQX $(10 \mu \mathrm{M})$ does not modify the increase in synaptophysin evoked by NP1 knockdown (Fig. 8D). In contrast, both TTX and CNQX completely blocked the effect of NP1 knockdown on PSD95 (Fig. 8D). These results indicate that the effect of NP1 knockdown on PSD95 protein levels is secondary to the change in synaptophysin protein levels and is mediated by AMPA receptor activation and provide further evidence in support that the increase in excitatory synapses evoked by shNP1 is initiated presynaptically.

NP1 knockdown increases the excitatory drive and synaptic strength in alert behaving mice

To investigate whether the increase in excitatory synapse number evoked by NP1 knockdown influences synaptic potentiation, we measured input-output curves and LTP at the CA3-CA1 synapse in alert behaving animals (Figs. 9A,B). High-titer lentiviral vectors expressing shNP1 or shRdm (as a control) were intracranially injected into the CA1 area of the right hippocampus of mice, and LTP was induced. As both constructs allow the bicistronic expression of an eGFP marker, we confirmed the level and distribution of the shRNA vector expression by confocal fluorescence microscopy. Both vectors were expressed at comparable levels and eGFP expression was detectable at sites both near and distal to the injection site throughout the hippocampus, both in cell bodies and in neurites (results not shown). To confirm the ability of the shNP1 lentiviral vector to knockdown NP1 expression, we measured NP1 protein levels in the entire right hippocampus immediately after LTP by Western blot analysis. The NP1 levels of the whole hippocampus, that includes areas not accessible to the virus particles, in mice treated with the shNP1 lentiviral vector were significantly lower (by 30\%) than those treated with the control shRdm vector.

The modulation of fEPSPs evoked by the presentation of a pair of pulses is a typical presynaptic short-term plastic property of some excitatory synapses (Zucker and Regehr, 2002). Paired-pulse stimulation of Schaffer collaterals using low intensity stimuli, over a wide range (20-100 ms) of interstimulus intervals, caused a similar facil- 
A
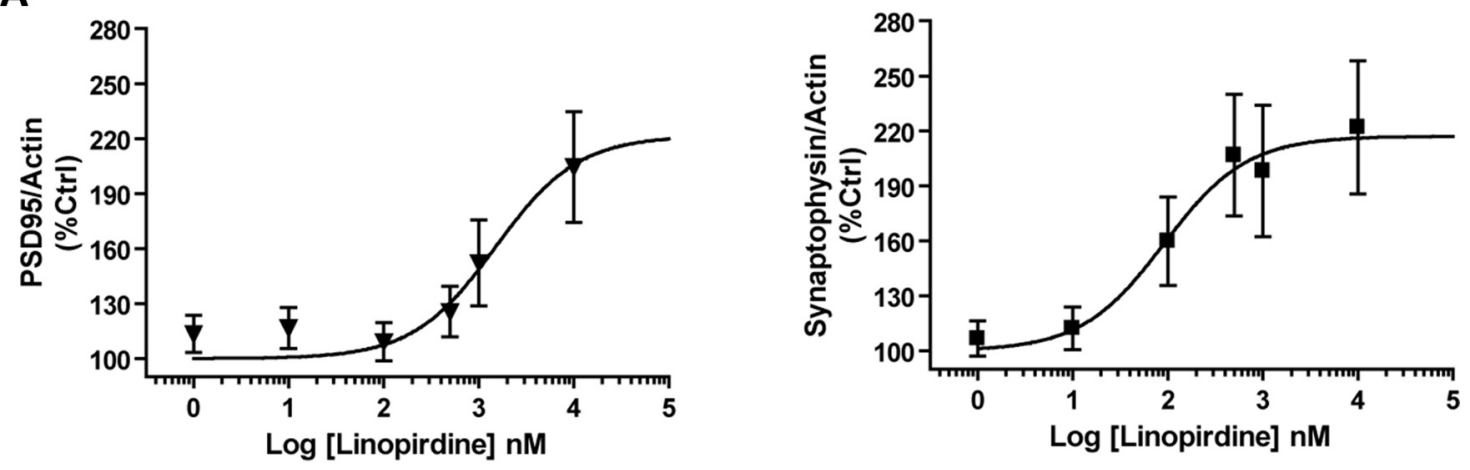

B
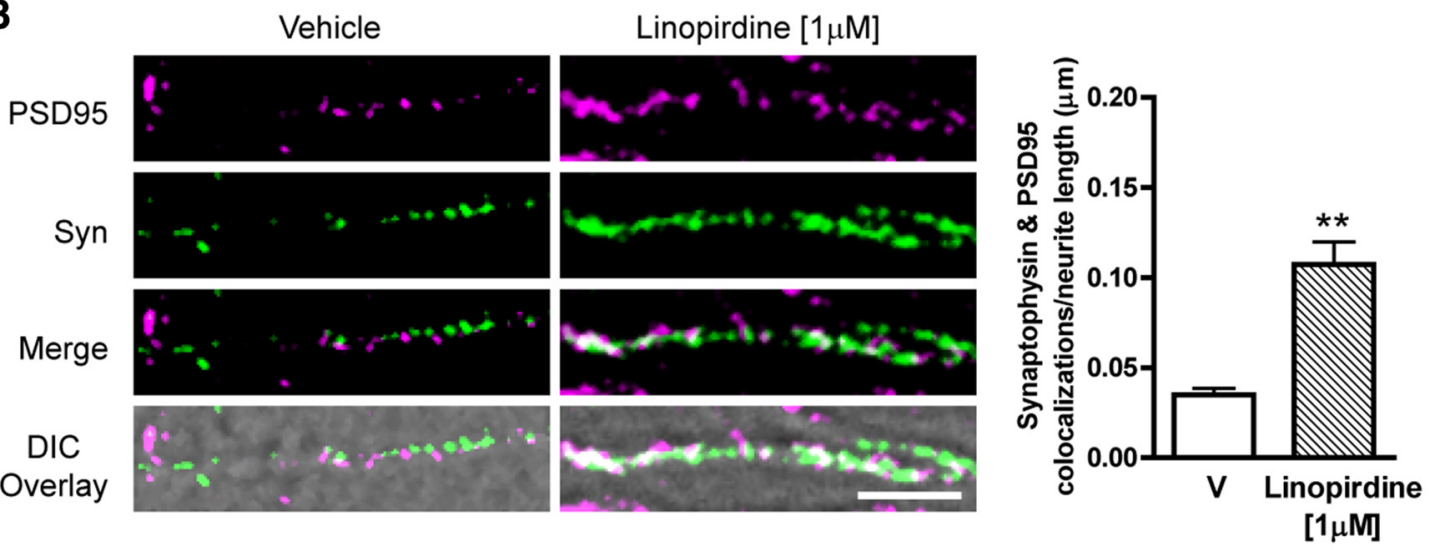

C
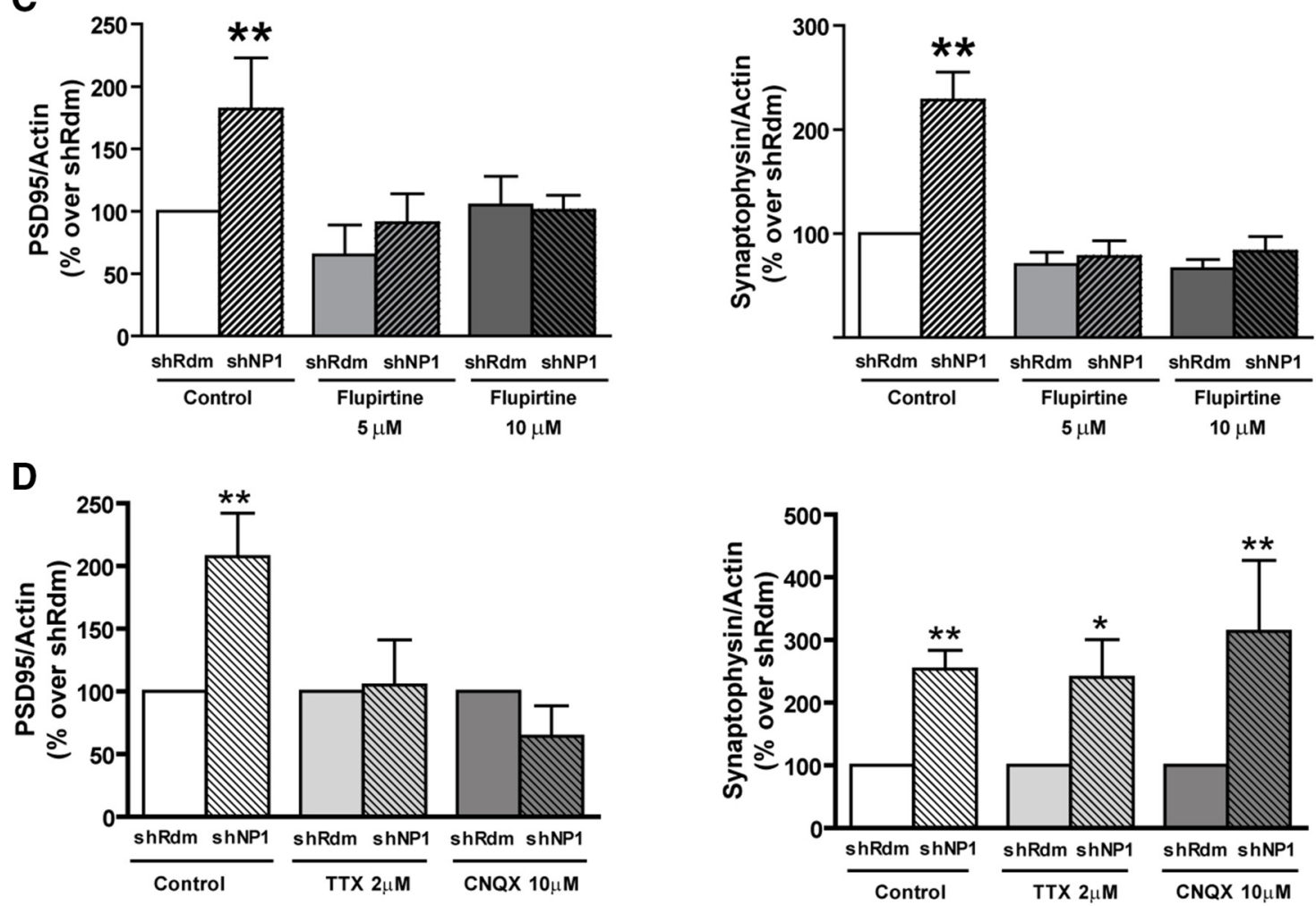

Figure 8. Influence of Kv7.2 channels and excitatory neurotransmission on the increase in synaptic proteins evoked by NP1 knockdown. Cortical neuronal cultures were treated with different concentrations of the Kv7 channel antagonist linopirdine $(\boldsymbol{A})$ or the Kv7 channel opener flupirtine $(\boldsymbol{C})$ at the day of plating. PSD95 and synaptophysin protein levels were measured by Western blotting, normalized to actin levels, and expressed as percentage control. Values are mean \pm SEM from $n=7$ independent experiments. $\boldsymbol{B}$, Effect of linopirdine (1 $\mu \mathrm{M})$ on synapse density. Representative images of PSD95 (magenta) and synaptophysin (Syn; green) colocalizations (white) overlaid onto the corresponding DIC image (scale bar, $5 \mu \mathrm{m}$ ) and quantitative analysis of the number of PSD95 and synaptophysin colocalizations per neurite length. The total number of fields are $n=11$ per group [ ${ }^{*}$ significantly different from vehicle (V); $p<0.001$, Student's $t$ test, two-tailed]. D, Cortical neuronal cultures were treated with tetrodotoxin $(2 \mu \mathrm{M})$ or CNQX (10 $\mu \mathrm{m})$ on the day of plating. Quantitative analysis of NP1 knockdown on (Figure legend continues.) 
A

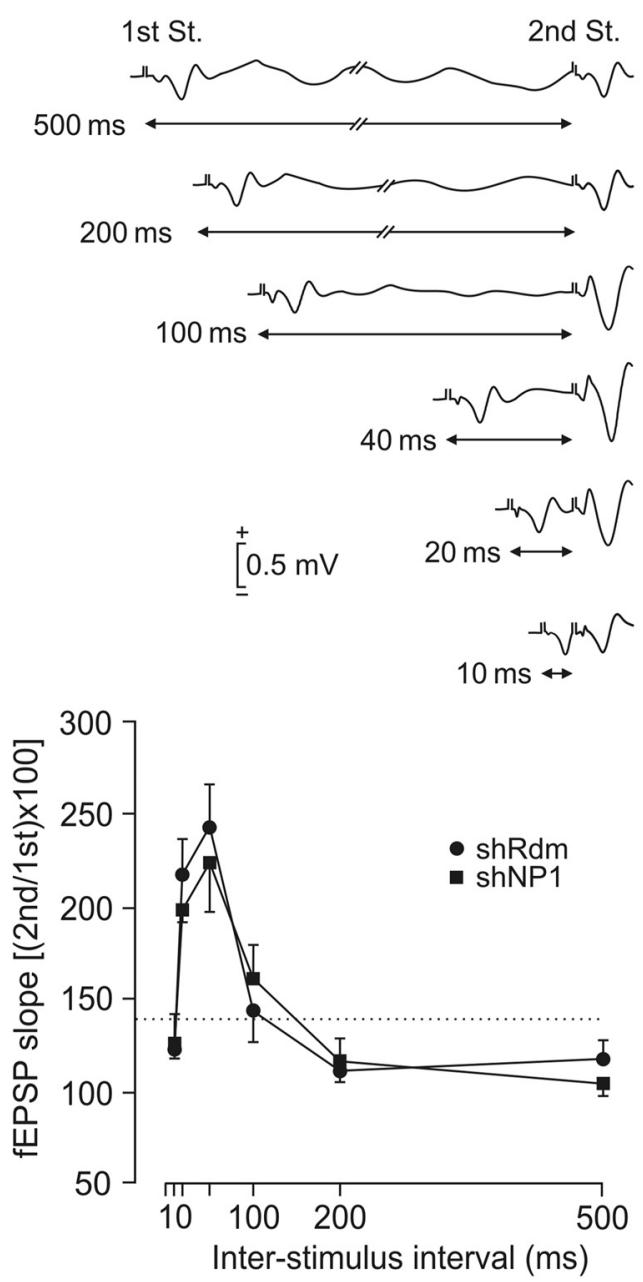

B
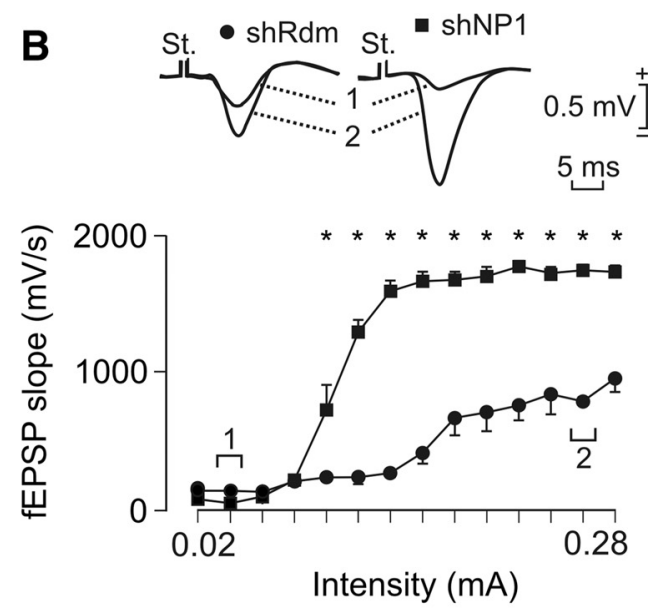

C

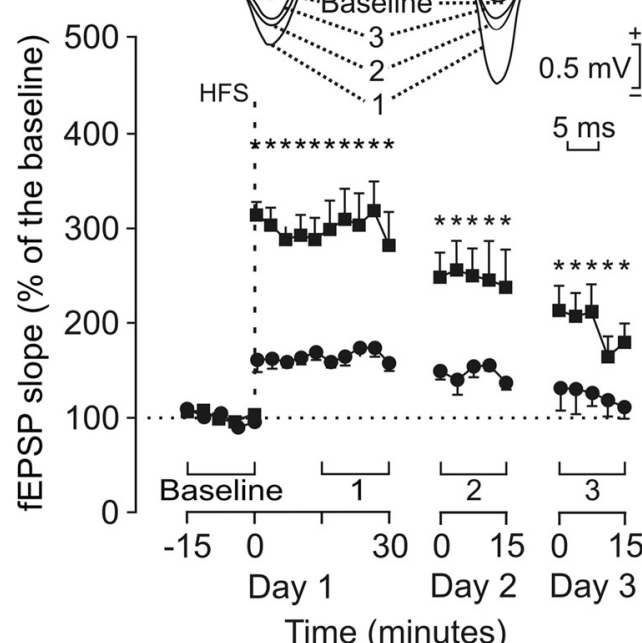

Figure 9. Knockdown of NP1 potentiates input/output curve and LTP and does not modify paired-pulse facilitation in the hippocampus of behaving mice. $\boldsymbol{A}$, Comparison of paired-pulse facilitation between NP1 and control mice. The data shown are mean \pm SEM slopes of the second fEPSP expressed as a percentage of the first for six interstimulus intervals. Both control shRdm (black circles) and shNP1 (black squares) mice presented similar paired-pulse facilitation at intervals of $20-500$ ms using intensities indicated in (1) in $\boldsymbol{B}$ and $\boldsymbol{C}$, respectively. Top, Some fEPSP paired traces collected from a representative NP1 knockdown mouse are shown. $\boldsymbol{B}$, Input- output curves for the CA3-CA1 synapse. Single pulses were presented to Schaffer collaterals at increasing intensities while recording evoked fEPSPs at the CA1 area in control shRdm (black circles) and in shNP1 (black squares) mice. Representative fEPSPs collected from the two types of mouse are illustrated at the indicated times $(1,2)$. Values are mean \pm SEM $(n=5)$. fEPSPs evoked by Schaffer collateral stimulation in NP1 knockdown animals were significantly larger $(p<0.001)$ than those collected from controls for intensities $>0.1 \mathrm{~mA}$. C, Top, Illustrated examples of fEPSPs evoked by single pulses in selected control (black circles) and NP1 knockdown (black squares) animals before (baseline) and after (1-3) HFS of Schaffer collaterals. The bottom graphs illustrate the time course of LTP evoked in the CA1 area (fEPSP mean \pm SEM) by single pulses following HFS for shRdm and shNP1 mice. HFS was presented after 15 min of baseline recordings, at the time marked by the dashed line. fEPSPs are given as a percentage of the baseline (100\%) slope. Although the two groups presented a significant ( $p \leq 0.01$ ) increase (ANOVA, two-tailed) in fEPSP slope following HFS, values evoked in NP1 knockdown mice ( 9 animals) were significantly ( $p<0.001)$ larger than those collected from controls $(n=9)$ for the whole set of records.

itation of the fEPSP evoked by the second pulse over the fEPSP evoked by the first in control and NP1 knockdown mice (Fig. 9A). Comparison of the fEPSPs evoked in control and shNP1 mice by the first pulse shows that they were significantly larger in NP1 knockdown mice at intensities $>0.1 \mathrm{~mA}$ (Fig. 9B). Moreover, in agreement

(Figure legend continued.) synaptophysin and PSD95 protein levels expressed as percentage control. Actin was used as control for protein loading. Values are mean \pm SEM from at least $n=$ 3 independent experiments. PSD95: shRdm/Control, $n=17 ;$ shNP1/Control, $n=7$; shRdm/ TTX, $n=9 ;$ shNP1/TTX, $n=6$; shRdm/CNQX, $n=3$; shNP1/CNQX, $n=3$. Synaptophysin: shRdm/Control, $n=17$; shNP1/Control, $n=7$; shRdm/TTX, $n=9$; shNP1/TTX, $n=8 ;$ shRdm/ CNQX, $n=3$; shNP1/CNQX, $n=3{ }^{* *} p<0.01$, one-way ANOVA with Bonferroni post hoc tests.) with previous descriptions of LTP evoked at the CA3-CA1 synapse in behaving mice (Gruart et al., 2006), the application of highfrequency stimulation (HFS) to control animals produced significant LTP, but knockdown of NP1 markedly enhanced LTP compared with controls (Fig. 9C). Indeed, LTP was significantly larger in shNP1 treated mice compared with controls (Fig. 9C). These results obtained in vivo in the behaving mice indicate that knockdown of NP1 elicits a notable increase in excitatory drive at the CA3-CA1 synapse and that NP1 is a limiting factor for LTP.

\section{Discussion}

Here, we report that NP1 restricts the formation of excitatory synapses and dendritic protrusions, revealing a new and unexpected function for NP1. We found that knockdown of NP1 increases neu- 
ronal excitability and synaptic plasticity by increasing the number (Fig. $2 B$ ), but not the efficacy, of excitatory synapses because knockdown of NP1 significantly increased the frequency of excitatory mEPSCs, but did not modify their amplitude (Figs. 4C-G).

The finding that NP1 negatively regulates excitatory synapse formation contrasts with the previously reported positive synaptogenic effect of NP2 (Tsui et al., 1996; Bjartmar et al., 2006), another member of the long neuronal pentraxins family. However, the present findings are consistent with previous reports showing that these two homologous neuronal pentraxins are regulated in an opposite way by neuronal activity (Tsui et al., 1996; DeGregorio-Rocasolano et al., 2001). These two neuronal pentraxins have been shown to mediate different processes regulated by different levels of neuronal activity: NP2 contributes to activitydependent synaptogenesis and synaptic refinement (Xu et al., 2003), whereas NP1 is part of the intrinsic program of neuronal apoptosis evoked by low neuronal activity (DeGregorio-Rocasolano et al., 2001). The observation that NP1 limits excitatory synaptogenesis, an effect that is contrary to what has been previously reported for NP2, provides support to the hypothesis that these two neuronal pentraxins oppositely regulate the density of synaptic contacts as part of an activity-dependent genetic switch in which NP1 acts to restrict synapse formation.

In addition, the results reported here show that NP1 interacts with Kv7.2, a subunit of slow-rectifying voltage-gated Kv7 potassium channels, regulating the surface expression of these channels and neuronal excitability. These channels produce the muscarine-sensitive $\mathrm{K}^{+}$current (M-current), a slowly activating and noninactivating current that suppresses neuronal excitability, acting as a brake for repetitive firing in different types of neurons (Wang et al., 1998). The finding that knockdown of NP1 reduces the surface expression of Kv7.2 and the M-current, coupled with the observation that pharmacological inhibition of the M-current with linopirdine mimics, whereas activation with flupirtine prevents, the effect of NP1 knockdown on synaptic proteins, supports the interpretation that NP1 acts as a negative regulator of excitatory synapses by suppressing neuronal excitability through Kv7.2 channels.

The finding that the interaction of NP1 with Kv7.2 channels is restricted to the Kv7.2 subunit was initially unexpected because, in neurons, most Kv7/M-channels are hetero-tetramer complexes composed of Kv7.2 and Kv7.3 subunits (Wang et al., 1998) that are expressed on cell bodies and dendrites of CNS neurons and sympathetic ganglia (Cooper et al., 2000). However, there is evidence indicating the existence of homomeric Kv7 channels composed of Kv7.2 subunits and that Kv7.2 and Kv7.3 do not always colocalize (Hadley et al., 2003; Devaux et al., 2004). Interestingly, Kv7.2 has been shown to be expressed presynaptically on axons and nerve terminals of specific subsets of neurons and it has been reported that Kv7.2 but not Kv7.3 subunits regulate neurotransmitter release (Cooper et al., 2001; Martire et al., 2004). Consequently, the specific interaction of NP1 with the Kv7.2 subunit might preferentially influence presynaptic homomeric Kv7.2 channels. In support of this interpretation, a previous study has shown that Kv7.2, but not Kv7.3, binds to syntaxin $1 \mathrm{~A}$ and that these two proteins colocalize at hippocampal presynaptic varicosities (Regev et al., 2009).

Based on this previous study, we performed reciprocal coimmunoprecipitation studies in brain tissue and confirmed that NP1 interacts with both Kv7.2 and syntaxin 1A native proteins (Figs. 5A,B). Subsequent experiments with recombinant proteins established that NP1 does not bind directly to syntaxin 1A and that the interaction of NP1 with syntaxin 1A is through
Kv7.2. In previous biotinylation experiments in cultured neurons labeling membrane proteins with extracellular exposed residues we could not detect significant amounts of NP1 in the extracellular side of the neuronal membrane (Clayton et al., 2012). This observation, coupled with the finding that syntaxin 1A binds the C terminus of Kv7.2 channels, suggests that NP1 binds the Kv7.2/ syntaxin complex in the intracellular compartment. Moreover, consistently with previous reports showing that Kv7.2 is expressed presynaptically on axons and nerve terminals (Cooper et al., 2001), our confocal immunofluorescence studies in primary neuronal cultures confirmed that some puncta of Kv7.2 immunoreactivity colocalize with the excitatory presynaptic marker VGLUT1. Likewise, NP1 and Kv7.2 colocalize in VGLUT1positive presynaptic terminals, indicating that the interaction of NP1 with Kv7.2 occurs at excitatory synapses. These results are consistent with our finding that knockdown of NP1 increases the number of excitatory, but not inhibitory, synapses. Moreover, the observation that NP1/Kv7.2 colocalize in growth cones (Fig. 5F) and that the NP1/Kv7.2 complex colocalizes with VGLUT1 (Fig. $5 E)$, together with the finding that syntaxin $1 \mathrm{~A}$ coimmunoprecipitates both NP1 and Kv7.2 from brain tissue (Fig. 5B), suggests that NP1 forms a complex with Kv7.2 and syntaxin 1A in the presynaptic compartment of excitatory synapses. Because NP1 expression is regulated by neuronal activity, we propose a model by which the NP1-Kv7.2-syntaxin 1A complex is a molecular mechanism that limits the number of excitatory synapses in an activity-dependent manner, probably through modulation of neurotransmitter release. In support of this interpretation, increasing Kv7.2 channel function with flupirtine blocks the effect of shNP1 on synaptic proteins and previous work has shown that flupirtine inhibits calcium-dependent glutamate release (Sun and Kapur, 2012).

The increase in the number of excitatory synapses after knockdown of NP1 is remarkable and shows that cortical neurons in culture can make a much higher number of synapses when the restriction imposed by NP1 is removed. The higher number of excitatory synapses evoked by removing the limitation imposed by NP1 causes in turn the localization of extrasynaptic amino acid receptors to the new synapses (Figs. $4 A, B$ ). Moreover, the higher frequency mEPSCs and the increase in the amplitude of spontaneous calcium oscillations observed after the knockdown of NP1 reveal that the new synapses are functional. Several lines of evidence indicate that the change in the number of excitatory synapses is secondary to the presynaptic regulation of Kv7 channel activity by NP1. First, the reduction in surface expression of Kv7.2 subunit-containing channels caused by shNP1 knockdown leads to a decrease in the M-type potassium channel current (Fig. 6D). Second, presynaptic M-channels composed of Kv7.2, but not Kv7.3, subunits have been shown to regulate neurotransmitter release (Martire et al., 2004; Peretz et al., 2007). Moreover, activation of M-channels by a channel opener decreases the frequency of mEPSCs, without affecting their amplitude, suggesting that M-channels presynaptically inhibit glutamate release (Peretz et al., 2007). Notably, the knockdown of NP1 exhibits the opposite effect on the M-type potassium current and on the frequency of mEPSCs. Therefore, to assess the cause-effect relationship between the action of NP1 on the M-current and the regulation of synapse number, we investigated the effect of pharmacological modulation of Kv7 channels on synaptic proteins and synapse density. We found that the M-channel inhibitor linopirdine mimics, whereas the channel opener flupirtine rescues, the effects of NP1 knockdown on synaptic proteins. In addition, previous work has shown that linopirdine enhances LTP (Lampe et al., 
1997), an effect that is consistent with the increase in synaptic proteins and synapse number evoked by linopirdine found in our studies (Figs. 8A,B) and reminiscent of the enhanced LTP that we observe after NP1 knockdown (Fig. 9). Overall, these results indicate that NP1 negatively regulates excitatory synapse number by a mechanism that involves modulation of cell surface expression of Kv7 channels.

We also found that knockdown of NP1 increases excitatory drive and LTP in the hippocampus of alert behaving mice. This in vivo functional outcome of NP1 downregulation supports the interpretation that NP1 is a restrictive factor for activitydependent synaptic plasticity. The observation that NP1 knockdown increases excitatory drive in vivo (Fig. 9B) is consistent with the increase in the frequency, but not the amplitude, of mEPSCs elicited by downregulation of NP1 in cultured neurons (Fig. 4F) and suggests that NP1 regulates excitatory drive by limiting the number of functional excitatory synapses. The enhanced LTP found after knockdown of NP1 in vivo also supports the interpretation that NP1 is a limiting factor for synaptic plasticity. The effect of NP1 knockdown on LTP could be due to an increase in neurotransmitter release probability. However, further studies are necessary to identify the mechanisms by which NP1 regulates LTP in vivo. These results contrast with those of a previous study that found no difference in hippocampal basal synaptic transmission or LTP in double NP1/NP2 knock-out mice (Bjartmar et al., 2006). However, one possibility is that, in those mice, a positive effect on LTP caused by NP1 deletion might be cancelled by a negative effect of the simultaneous deletion of NP2.

The negative regulation of excitatory synapse number by NP1 reported here may have important implications in understanding the molecular mechanisms underlying chronic neurodegenerative diseases such as Alzheimer's disease. NP1 is increased in Alzheimer's brain (Abad et al., 2006) and may underlie the loss of synapses that is one of the hallmarks of Alzheimer's disease (Selkoe, 2002). In support of this hypothesis, overexpression of NP1 decreases the number of excitatory synapses (Fig. $2 B$ ), which is consistent with our previous observations showing that NP1 contributes to synapse loss, neurite damage, and the subsequent apoptotic toxicity induced by amyloid- $\beta$ in cortical neuronal cultures (Abad et al., 2006). Based on these data, we propose that reduction of NP1 expression may represent a target to prevent the synaptic dysfunction in neurodegenerative disorders.

\section{References}

Abad MA, Enguita M, DeGregorio-Rocasolano N, Ferrer I, Trullas R (2006) Neuronal pentraxin 1 contributes to the neuronal damage evoked by amyloid-beta and is overexpressed in dystrophic neurites in Alzheimer's brain. J Neurosci 26:12735-12747. CrossRef Medline

Abel T, Kandel E (1998) Positive and negative regulatory mechanisms that mediate long-term memory storage. Brain Res Brain Res Rev 26:360-378. CrossRef Medline

Abramoff MD, Magelhaes PJ, Ram SJ (2004) Image processing with ImageJ. Biophotonics Int 11:36-42.

Alaimo A, Gómez-Posada JC, Aivar P, Etxeberría A, Rodriguez-Alfaro JA, Areso P, Villarroel A (2009) Calmodulin activation limits the rate of KCNQ2 K+ channel exit from the endoplasmic reticulum. J Biol Chem 284:20668-20675. CrossRef Medline

Andrade R, Foehring RC, Tzingounis AV (2012) The calcium-activated slow AHP: cutting through the Gordian knot. Front Cell Neurosci 6:47. CrossRef Medline

Bailey CH, Kandel ER (2008) Synaptic remodeling, synaptic growth and the storage of long-term memory in Aplysia. Prog Brain Res 169:179-198. CrossRef Medline

Bjartmar L, Huberman AD, Ullian EM, Rentería RC, Liu X, Xu W, Prezioso J, Susman MW, Stellwagen D, Stokes CC, Cho R, Worley P, Malenka RC, Ball S, Peachey NS, Copenhagen D, Chapman B, Nakamoto M, Barres BA,
Perin MS (2006) Neuronal pentraxins mediate synaptic refinement in the developing visual system. J Neurosci 26:6269-6281. CrossRef Medline

Bliss TV, Gardner-Medwin AR (1973) Long-lasting potentiation of synaptic transmission in the dentate area of the unanaestetized rabbit following stimulation of the perforant path. J Physiol 232:357-374. CrossRef Medline

Brown DA (2008) Kv7 (KCNQ) potassium channels that are mutated in human diseases. J Physiol 586:1781-1783. CrossRef Medline

Brown DA, Passmore GM (2009) Neural KCNQ (Kv7) channels. Br J Pharmacol 156:1185-1195. CrossRef Medline

Caroni P, Donato F, Muller D (2012) Structural plasticity upon learning: regulation and functions. Nat Rev Neurosci 13:478-490. CrossRef Medline

Chen B, Bixby JL (2005) A novel substrate of receptor tyrosine phosphatase PTPRO is required for nerve growth factor-induced process outgrowth. J Neurosci 25:880-888. CrossRef Medline

Clayton KB, Podlesniy P, Figueiro-Silva J, López-Domenech G, Benitez L, Enguita M, Abad MA, Soriano E, Trullas R (2012) NP1 regulates neuronal activity-dependent accumulation of BAX in mitochondria and mitochondrial dynamics. J Neurosci 32:1453-1466. CrossRef Medline

Cooper EC, Aldape KD, Abosch A, Barbaro NM, Berger MS, Peacock WS, Jan YN, Jan LY (2000) Colocalization and coassembly of two human brain M-type potassium channel subunits that are mutated in epilepsy. Proc Natl Acad Sci U S A 97:4914-4919. CrossRef Medline

Cooper EC, Harrington E, Jan YN, Jan LY (2001) M channel KCNQ2 subunits are localized to key sites for control of neuronal network oscillations and synchronization in mouse brain. J Neurosci 21:9529-9540. Medline

DeGregorio-Rocasolano N, Gasull T, Trullas R (2001) Overexpression of neuronal Pentraxin 1 is involved in neuronal death evoked by low $\mathrm{K}+$ in cerebellar granule cells. J Biol Chem 276:796-803. CrossRef Medline

Devaux JJ, Kleopa KA, Cooper EC, Scherer SS (2004) KCNQ2 is a nodal K+ channel. J Neurosci 24:1236-1244. CrossRef Medline

D’Mello SR, Galli C, Ciotti T, Calissano P (1993) Induction of apoptosis in cerebellar granule neurons by low potassium- inhibition of death by insulin-like growth factor-I and cAMP. Proc Natl Acad Sci U S A 90: 10989-10993. CrossRef Medline

Fath T, Ke YD, Gunning P, Götz J, Ittner LM (2009) Primary support cultures of hippocampal and substantia nigra neurons. Nat Protoc 4:78-85. CrossRef Medline

Gewurz H, Zhang XH, Lint TF (1995) Structure and function of the pentraxins. Curr Opin Immunol 7:54-64. CrossRef Medline

Gruart A, Muñoz MD, Delgado-García JM (2006) Involvement of the CA3CA1 synapse in the acquisition of associative learning in behaving mice. J Neurosci 26:1077-1087. CrossRef Medline

Grynkiewicz G, Poenie M, Tsien RY (1985) A new generation of $\mathrm{Ca}^{2+}$ indicators with greatly improved fluorescence properties. J Biol Chem 260: 3440-3450. Medline

Gureviciene I, Ikonen S, Gurevicius K, Sarkaki A, van Groen T, Pussinen R, Ylinen A, Tanila H (2004) Normal induction but accelerated decay of LTP in APP + PS1 transgenic mice. Neurobiol Dis 15:188-195. CrossRef Medline

Hadley JK, Passmore GM, Tatulian L, Al-Qatari M, Ye F, Wickenden AD, Brown DA (2003) Stoichiometry of expressed KCNQ2/KCNQ3 potassium channels and subunit composition of native ganglionic $\mathrm{M}$ channels deduced from block by tetraethylammonium. J Neurosci 23:5012-5019. Medline

Holtmaat A, Svoboda K (2009) Experience-dependent structural synaptic plasticity in the mammalian brain. Nat Rev Neurosci 10:647-658. CrossRef Medline

Kerchner GA, Nicoll RA (2008) Silent synapses and the emergence of a postsynaptic mechanism for LTP. Nat Rev Neurosci 9:813-825. CrossRef Medline

Kneussel M, Betz H (2000) Receptors, gephyrin and gephyrin-associated proteins: novel insights into the assembly of inhibitory postsynaptic membrane specializations. J Physiol 525:1-9. CrossRef Medline

Lamas JA, Selyanko AA, Brown DA (1997) Effects of a cognition-enhancer, linopirdine (DuP 996), on M-type potassium currents (IK(M)) and some other voltage- and ligand-gated membrane currents in rat sympathetic neurons. Eur J Neurosci 9:605-616. CrossRef Medline

Lampe BJ, Gaskill JL, Keim SC, Brown BS (1997) Linopirdine reduces stimulus intensity threshold for induction of long-term potentiation in the 
Schaffer collateral/CA1 pathway in rat hippocampal slices. Neurosci Lett 222:135-137. CrossRef Medline

Martire M, Castaldo P, D’Amico M, Preziosi P, Annunziato L, Taglialatela M (2004) M channels containing KCNQ2 subunits modulate norepinephrine, aspartate, and GABA release from hippocampal nerve terminals. J Neurosci 24:592-597. CrossRef Medline

Meijering E, Jacob M, Sarria JC, Steiner P, Hirling H, Unser M (2004) Design and validation of a tool for neurite tracing and analysis in fluorescence microscopy images. Cytometry A 58:167-176. CrossRef Medline

O’Brien RJ, Xu D, Petralia RS, Steward O, Huganir RL, Worley P (1999) Synaptic clustering of AMPA receptors by the extracellular immediateearly gene product Narp. Neuron 23:309-323. CrossRef Medline

O’Brien R, Xu D, Mi R, Tang X, Hopf C, Worley P (2002) Synaptically targeted narp plays an essential role in the aggregation of AMPA receptors at excitatory synapses in cultured spinal neurons. J Neurosci 22:44874498. Medline

Paxinos G, Watson C (1986) The rat brain in stereotaxic coordinates. London: Academic.

Peretz A, Sheinin A, Yue C, Degani-Katzav N, Gibor G, Nachman R, Gopin A, Tam E, Shabat D, Yaari Y, Attali B (2007) Pre- and postsynaptic activation of M-channels by a novel opener dampens neuronal firing and transmitter release. J Neurophysiol 97:283-295. CrossRef Medline

Pérez-Brangulí F, Muhaisen A, Blasi J (2002) Munc 18a binding to syntaxin $1 \mathrm{~A}$ and $1 \mathrm{~B}$ isoforms defines its localization at the plasma membrane and blocks SNARE assembly in a three-hybrid system assay. Mol Cell Neurosci 20:169-180. CrossRef Medline

Regev N, Degani-Katzav N, Korngreen A, Etzioni A, Siloni S, Alaimo A, Chikvashvili D, Villarroel A, Attali B, Lotan I (2009) Selective interaction of syntaxin 1A with KCNQ2: possible implications for specific modulation of presynaptic activity. PLoS One 4:e6586. CrossRef Medline

Schlimgen AK, Helms JA, Vogel H, Perin MS (1995) Neuronal pentraxin, a secreted protein with homology to acute phase proteins of the immune system. Neuron 14:519-526. CrossRef Medline

Selkoe DJ (2002) Alzheimer's disease is a synaptic failure. Science 298:789791. CrossRef Medline

Shahidullah M, Santarelli LC, Wen H, Levitan IB (2005) Expression of a calmodulin-binding KCNQ2 potassium channel fragment modulates neuronal M-current and membrane excitability. Proc Natl Acad Sci U S A 102:16454-16459. CrossRef Medline
Sia GM, Béïque JC, Rumbaugh G, Cho R, Worley PF, Huganir RL (2007) Interaction of the N-terminal domain of the AMPA receptor GluR4 subunit with the neuronal pentraxin NP1 mediates GluR4 synaptic recruitment. Neuron 55:87-102. CrossRef Medline

Sun J, Kapur J (2012) M-type potassium channels modulate Schaffer collateral-CA1 glutamatergic synaptic transmission. J Physiol 590:39533964. CrossRef Medline

Tada T, Sheng M (2006) Molecular mechanisms of dendritic spine morphogenesis. Curr Opin Neurobiol 16:95-101. CrossRef Medline

Tanaka T, Saito H, Matsuki N (1996) Intracellular calcium oscillation in cultured rat hippocampal neurons: a model for glutamatergic neurotransmission. Jpn J Pharmacol 70:89-93. CrossRef Medline

Tseng LA, Bixby JL (2011) Interaction of an intracellular pentraxin with a BTB-Kelch protein is associated with ubiquitylation, aggregation and neuronal apoptosis. Mol Cell Neurosci 47:254-264. CrossRef Medline

Tsui CC, Copeland NG, Gilbert DJ, Jenkins NA, Barnes C, Worley PF (1996) Narp, a novel member of the pentraxin family, promotes neurite outgrowth and is dynamically regulated by neuronal activity. J Neurosci 16 : 2463-2478. Medline

Tzingounis AV, Nicoll RA (2008) Contribution of KCNQ2 and KCNQ3 to the medium and slow afterhyperpolarization currents. Proc Natl Acad Sci U S A 105:19974-19979. CrossRef Medline

Wang HS, Pan Z, Shi W, Brown BS, Wymore RS, Cohen IS, Dixon JE, McKinnon D (1998) KCNQ2 and KCNQ3 potassium channel subunits: molecular correlates of the M-channel. Science 282:1890-1893. CrossRef Medline

West AE, Griffith EC, Greenberg ME (2002) Regulation of transcription factors by neuronal activity. Nat Rev Neurosci 3:921-931. CrossRef Medline

Xu D, Hopf C, Reddy R, Cho RW, Guo L, Lanahan A, Petralia RS, Wenthold RJ, O'Brien RJ, Worley P (2003) Narp and NP1 form heterocomplexes that function in developmental and activity-dependent synaptic plasticity. Neuron 39:513-528. CrossRef Medline

Yuan LL, Chen X (2006) Diversity of potassium channels in neuronal dendrites. Prog Neurobiol 78:374-389. CrossRef Medline

Zucker RS, Regehr WG (2002) Short-term synaptic plasticity. Annu Rev Physiol 64:355-405. CrossRef Medline 